Universidade de Brasília - UnB

Departamento de Economia

\title{
REVISÃO DE LITERATURA SOBRE OS SETORES DE INFRAESTRUTURA BRASILEIROS
}

Heitor Araújo e Castro

Orientador: José Guilherme de Lara Resende 
Heitor Araújo e Castro

\title{
REVISÃO DE LITERATURA SOBRE OS SETORES DE INFRAESTRUTURA BRASILEIROS
}

\begin{abstract}
Monografia apresentada ao Departamento de Economia da Universidade de Brasília (UnB) como requisito parcial à obtenção do grau de Bacharel em Ciências Econômicas.
\end{abstract}

Banca Examinadora:

Professor José Guilherme de Lara Resende (orientador)

Professora Geovana Lorena Bertussi

Brasília

2018 
Dedico essa monografia ao meu amado avô Paulo, modelo de ser humano e amigo que, com sua dedicação e esforço, possibilitou meu desenvolvimento intelectual e humano. Sem ele, certamente, eu não estaria aqui. Também dedico essa monografia a Giovanna Yolle Silva de Jesus que, com seu carinho e afeto, me ajudou na fase mais difícil da minha vida. 


\section{Agradecimentos}

Agradeço, primeiramente, a Deus por me ajudar a superar mais essa etapa de amadurecimento em minha vida.

Agradeço à minha família e amigos que, de alguma forma, estiveram comigo nesses anos de estudo. Em especial, agradeço à minha mãe Mônica Marques de Araújo pela dedicação durante todos esses anos e ao meu avô Paulo Raimundo Ramos de Araújo pelo seu carinho incondicional. Gostaria de agradecer aos meus irmãos que, por várias vezes, me expuseram a opiniões divergente e me ajudaram a crescer como ser humano.

Agradeço à coach Ellen Piedade pela imensa ajuda no momento em que achava não ser capaz de suplantar as dificuldades do curso.

Agradeço também aos meus professores, em especial, a José Guilherme de Lara Resende e Adriana Amado pela atenção em momentos turbulentos da graduação e estudo para a ANPEC.

Agradeço à professora Geovana Bertussi pela disposição em fazer parte da banca e também contribuir para o trabalho.

Por fim, agradeço a todos os amigos que fiz durante meu período na Universidade de Brasília, vocês me ajudaram muito nessa estada e, com certeza, a deixaram muito mais leve. 


\section{RESUMO}

O objetivo da pesquisa é analisar o estado atual da infraestrutura no Brasil. O trabalho demonstra a importância do investimento em infraestrutura para o desenvolvimento de longo prazo do país. Apresenta as principais políticas voltadas aos setores de energia e saneamento, os investimentos realizados ao longo das últimas décadas para os setores, estado atual e as mudanças promovidas pelo Programa de Aceleração do Crescimento (PAC). Os resultados da pesquisa demonstram que a infraestrutura brasileira apresenta vários problemas se comparada a de outros países da América Latina e de mesmo nível econômico. O trabalho conclui que o problema está ligado ao não cumprimento do que foi proposto, além de erros nos projetos e aumento excessivo de prazos e custos.

Palavras-chave: saneamento básico, energia, investimento, PAC. 


\begin{abstract}
The objective of this research is to analyze the current state of infrastructure in Brazil. This work shows the importance of the investment in infrastructure for the long term development of the country. It introduces the main policies towards the energy and basic sanitation sectors, current state and changes promoted by Programa de Aceleração do Crescimento (PAC). The results of this research demonstrate that the brazilian infrastructure has many problems if compared to other countries in Latin America with the same economic level. This paper concludes that the main problems are the non fulfillment of what was proposed, errors in projects and excessive increase in deadlines and costs.
\end{abstract}

Keywords: basic sanitation, energy, investment, PAC. 


\section{SUMÁRIO}

Introdução ..............................................................................................................................................10

1- Revisão de Literatura Brasileira e Estudos Relevantes ......................................................12

2- Análise do Setor Elétrico Brasileiro....................................................................................17

2.1 Considerações Gerais sobre o Setor Elétrico .........................................................................17

2.2 Panorama Histórico do Setor Elétrico.........................................................................................17

2.3 Atual Situação do Setor Elétrico ..............................................................................................20

3- Análise sobre o Setor de Saneamento no Brasil.....................................................................23

3.1 Considerações Gerais sobre o Setor de Saneamento Básico...............................................23

3.2 Panorama Histórico do Setor de Saneamento Básico ...........................................................24

3.3 Atual Situação do Setor de Saneamento Básico.....................................................................27

4-Avaliação sobre os Impactos e Investimentos Realizados pelo Programa de Aceleração do Crescimento (PAC) ...................................................................................................................32

4.1 Consideraçø̃es Gerais sobre o Programa ...............................................................................32

4.2 Avaliação dos Investimentos Realizados pelo Programa de Aceleração do Crescimento (PAC) .................................................................................................................................33

4.3 Avaliação dos Impactos do PAC 1 e PAC 2 por Setor .........................................................36

4.3.1 Saneamento ……......................................................................................................................36

4.3.2 Transportes ...................................................................................................................................37

4.3.3 Mobilidade Urbana …….....................................................................................................................38

4.3.4 Energia Elétrica ...................................................................................................................39

Conclusão …................................................................................................................................40

Referências Bibliográficas .................................................................................................42 


\section{LISTA DE GRÁFICOS}

Gráfico 1 - Participação no consumo final energético por setor em 2012 página 21

Gráfico 2 - Investimentos em saneamento básico (\% PIB) no Brasil, de 1970 a 2005 página 28

Gráfico 3 - Custos logísticos como \% do PIB

página 38 


\section{Lista DE TABELAS}

Tabela 1 - Investimento realizado no setor de saneamento básico em milhões de reais página 28

Tabela 2 - Nível de atendimento com rede de abastecimento de água, de coleta de esgoto e de tratamento de esgoto gerado por região do Brasil, no ano de 2014

página 29

Tabela 3 - Investimento em infraestrutura por setor (em bilhões) página 34 


\section{Introdução}

A literatura, em geral, aponta para a alta correlação entre taxa de crescimento e estoque em infraestrutura (Rigolon, 1998; Calderón e Servén, 2004; Ferreira, 1996; Ferreira e Maliagros, 1998). Além disso, o investimento em infraestrutura é essencial para a redução de desigualdades e pobreza (Calderón e Servén, 2004; Bertussi e Ellery, 2012). Entretanto, boa parte dos setores de infraestrutura brasileiros apresentam déficits comparativos em relação a outros países da América Latina e de mesmo poder econômico (Calderón e Servén, 2004; Frischtak, 2008; FGV, 2006).

A carência de investimento em infraestrutura está intimamente relacionada a vários problemas enfrentados pelo Brasil. A falta de investimento em saneamento, por exemplo, está relacionada com problemas em educação e saúde (Mcgranahan, 2015; Rasella, 2013; Scriptore et al, 2015). A carência de investimentos em mobilidade urbana influi diretamente no trânsito das grandes cidades, gerando prejuízos econômicos e reduzindo a produtividade brasileira (Pinheiro e Frischtak, 2015). Se o investimento em transportes é feito de maneira inadequada, os custos logísticos são maiores, gerando perda de competitividade para o país (Frischtak, 2016). Mesmo em setores onde o Brasil tem vantagens naturais, como no setor de energia elétrica, a falta de investimentos pode gerar crises no sistema, como em 2001 e 2014 (Sauer, 2015; Frischtak, 2016; IPEA, 2012; IPEA, 2010).

Para suplantar a falta de investimentos, em 2007 foi instituído o Programa de Aceleração do Crescimento (PAC). O programa visava a investir R \$ 414,5 bilhões nos setores de saneamento, transportes, telecomunicações e energia durante 4 anos (Frischtak, 2016). No entanto, até o final da primeira fase do programa (PAC 1), apenas uma fração desse investimento foi realizado. O programa sofreu com aumento de prazos e de custos, realizando apenas uma parte do que se propôs a fazer (Frischtak, 2016).

Com o intuito de terminar as obras inacabadas do PAC 1 e fazer novas obras, em meados de 2010, foi divulgado o PAC 2. Este programa vigorou entre os anos de 2011 e 2014 e sofreu os mesmos problemas da primeira fase (Frischtak, 2016).

Para entender a carência do estoque de infraestrutura brasileiro é necessário avaliar o panorama histórico e a atual situação de diversos setores de infraestrutura. Este trabalho se propõe a fazer a avaliação de dois destes setores: energia elétrica e saneamento básico. Posteriormente, faz uma análise geral do Programa de Aceleração do Crescimento, em suas duas fases (PAC 1 e PAC 2), discutindo investimentos realizados, impactos em cada setor e dificuldade na implementação e execução do programa. 
O horizonte temporal proposto é entre as décadas de 70 e a atual, com breves ponderações sobre décadas anteriores. O estudo cita as principais mudanças entre as décadas, sempre visando a avaliar como as alterações históricas influíram no estado atual da infraestrutura brasileira.

O presente trabalho é dividido em seis seções, incluindo esta introdução. A seção seguinte discute trabalhos teóricos e empíricos acerca do papel da infraestrutura na promoção do desenvolvimento econômico no Brasil (utiliza também trabalhos internacionais relevantes). A terceira seção discute o Setor de Energia no Brasil, dividindo o seu conteúdo em considerações gerais, panorama histórico e atual situação do setor. A quarta seção discute o Setor de Saneamento Básico no Brasil, utilizando a mesma estrutura proposta no capítulo anterior (considerações gerais, panorama histórico e atual situação do setor). A quinta seção avalia o Programa de Aceleração do Crescimento em suas duas fases (PAC 1 E PAC 2), discutindo investimentos realizados, impactos em cada setor e dificuldades na implementação e execução do programa. A última seção contém a conclusão. 


\section{1 - Revisão de Literatura Brasileira e Estudos Relevantes}

A evidência empírica afirma que o investimento brasileiro em infraestrutura é fundamental. O gasto no setor torna o país competitivo, reduz os custos marginais de instalação, operação e manutenção. No entanto, dependendo da região, o resultado por real investido varia, sendo mais eficaz em regiões mais pobres do território brasileiro como Norte, Nordeste e Centro Oeste (Bertussi, Ellery, 2012).

Gastos em saneamento, transportes e energia geram externalidades positivas, reduzindo o custo marginal de instalação, aumentando a qualidade de vida e possibilitando ganhos de produtividade. A aplicação em diferentes setores em infraestrutura é benéfica pois existem relações de complementariedade entre eles (Rigolon, 1998; Pêgo Filho, Cândido Jr. e Pereira, 1999).

Rigolon (1998) argumenta que investimentos em setores específicos de infraestrutura são responsáveis, não só por aumentar a quantidade, mas a qualidade dos serviços, além de impactar a produtividade dos fatores e reduzir os custos por unidade de insumo utilizado.

Os estudos em infraestrutura foram, a princípio, estimulados após resultados obtidos por Aschauer (1989). Na ocasião, o autor encontrou uma relação de causalidade entre aumento dos gastos públicos em infraestrutura e ganhos de produtividade do setor privado, bem como aumento do crescimento econômico.

Munnell (1992) estudou o efeito da expansão e qualidade da infraestrutura no aumento da produtividade de fatores privados. Os resultados indicam relação positiva, com ganhos em competitividade e maior oferta de produtos. Ao lado de Aschauer (1989), foi de preponderante importância para os primeiros trabalhos empíricos, investigando as relações entre infraestrutura e crescimento.

Calderón e Servén (2004) avaliaram o impacto dos setores de energia, transporte e telecomunicação na economia. No estudo, foram analisados dados de 121 países entre 1960 e 2000. Utilizaram, para isso, medidas de quantidade (volume) e de qualidade, bem como índices agregados e desagregados dos setores de infraestrutura.

Os autores encontraram uma relação positiva entre o estoque de infraestrutura e a taxa de crescimento do produto per capita das economias no longo prazo. Calderón e Servén (2004) também demonstraram que existe correlação positiva da qualidade da infraestrutura e o crescimento da renda. Encontrou-se, além disso, relação negativa e estatisticamente significante entre a quantidade e qualidade da infraestrutura e a desigualdade de renda. 
No Brasil, a relação entre crescimento e infraestrutura foi testada por Ferreira (1996), encontrando forte relação entre gastos públicos em infraestrutura e o produto de longo prazo da economia brasileira. No estudo, investigou o Produto interno real, numa regressão que utilizava a elasticidade de longo prazo dos investimentos realizados entre os anos de 1970 e 1993. O autor chegou a uma importante conclusão: a redução do ritmo de crescimento experimentado pelo Brasil no período se deveu, em parte, à redução do investimento em infraestrutura.

Ferreira e Maliagros (1998) investigaram a relação entre infraestrutura e crescimento agrupando dados sobre a economia brasileira entre os anos de 1950 e 1995 . Para isso, utilizaram o estudo de Ferreira (1996), abrangendo seu alcance, não somente em relação ao período de tempo, mas ao nível de agregação dos dados. Os resultados corroboraram os encontrados anteriormente. O crescimento de $10 \%$ no investimento em infraestrutura provocaria um aumento subsequente no produto do país no valor de 3,9\%. Além disso, uma importante contribuição foi a de elencar a efetividade do investimento em diferentes setores de infraestrutura. $\mathrm{O}$ investimento no setor de transporte tem maior eficácia que o investimento no setor elétrico, que, por sua vez, é mais eficiente que o investimento no setor de telecomunicações.

Silva e Fortunato (2007) avaliaram o impacto dos gastos públicos em infraestrutura sobre a taxa de crescimento de longo prazo da economia, dessa vez, porém, utilizando dados estaduais entre os anos de 1985 e 1998. Encontraram uma relação estatisticamente significante entre gastos em infraestrutura e desempenho macroeconômico dos estados. No estudo, um aumento de $10 \%$ nos gastos gera um crescimento subsequente no PIB per capita em $0,9 \%$. Silva e Fortunato (2007) também investigaram as diferenças de investimento em diferentes setores, um aumento nos gastos no setor de telecomunicações geraria, segundo o estudo, alta na taxa de crescimento superior a $3 \%$.

Jayme Jr. e Martins (2007) estudaram o impacto dos gastos governamentais em infraestrutura (transporte, energia e telecomunicações) e gastos no setor de transportes (isoladamente) na taxa de crescimento dos estados brasileiros entre os anos de 1986 e 2003. Segundo as análises, elevar $10 \%$ dos gastos em infraestrutura gera um aumento de 1,3\% na taxa de crescimento dos estados. O mesmo resultado foi encontrado quando se avaliou apenas o gasto no setor de transportes.

Mussolini e Teles (2010), por sua vez, testaram o impacto do aumento do capital de infraestrutura no estoque de capital privado e na produtividade total dos fatores (PTF), no longo prazo. Além disso, avaliaram o impacto de curto e médio prazo para estimar a relação de 
causalidade entre capital público/privado e produtividade. $\mathrm{O}$ trabalho utilizou dados bastante vastos em termos de horizonte temporal, compilados entre os anos de 1950 e 2000.

A inovação do trabalho de Mussolini e Teles (2010) se deveu à análise, não só do impacto do aumento de gastos em infraestrutura bancado pelo setor público na produtividade, mas também da relação entre capital público e capital privado. Encontraram relação de causalidade entre aumento do capital em infraestrutura e aumento da produtividade total dos fatores de produção.

Apesar do relativo consenso nos estudos empíricos sobre a relação entre infraestrutura e crescimento, existem trabalhos que encontram evidências contrárias. Gramlich (1994) considera as elasticidades-renda obtidas excessivamente altas. Para Ramirez (1994), a evidência empírica mostra que os investimentos públicos podem impactar negativamente o setor privado, caso haja má administração e excessivos subsídios às empresas estatais.

Tavares (2006) salienta que existe a possibilidade de órgãos e empresas estatais utilizarem recursos que, previamente, seriam utilizados pelo setor privado de forma mais eficiente. Desse modo, uma expansão de gastos por parte do poder público aumentaria a taxa de juros, afastando o investimento privado.

Candido Júnior (2001) avaliou o impacto entre gastos governamentais e crescimento do produto entre 1947 e 1995. Para isso, dividiu a economia em dois setores: privado e administrações públicas. Estudou o impacto dos gastos públicos de forma restrita (consumo do governo e transferência) e de forma ampla (consumo do governo, transferências e investimento das administrações públicas). No caso restrito, a elasticidade-renda encontrada foi negativa e estatisticamente insignificante. No caso amplo, a elasticidade-renda encontrada foi positiva e estatisticamente significante no valor de 0,43 . Outra contribuição importante do estudo foi estimar a diferença de produtividade entre o setor público e privado. O setor público é $40 \%$ menos produtivo que o setor privado (Candido Júnior, 2001).

A fim de mensurar o efeito da carga tributária e dos gastos públicos sobre a taxa de crescimento econômico das regiões brasileiras entre os anos de 1981 e 1995, Arraes e Teles (2001) utilizaram dados em painel num modelo inspirado no trabalho de Barro (1990). Para os autores, a carga tributária ótima deveria se situar entre $11 \%$ e $15 \%$ do Produto Interno Bruto (PIB). No entanto, para o ano de 95, somente 8 estados se encontravam nessa faixa de restrição.

Tanto no estudo de Candido Júnior (2001), quanto no estudo de Arraes e Teles, as conclusões são semelhantes: paga-se muito imposto no Brasil, o que estrangula a iniciativa privada. A saída, segundo os autores, é gastar menos e de forma mais eficiente. Segundo Arraes e Teles (2001), os gastos que apresentam maior elasticidade-renda são os em educação e cultura, 
seguidos por infraestrutura de transportes.

Barro (1991) explicita a forma como expansão dos gastos por parte do setor público pode prejudicar a economia. Agregando dados de 98 países entre os anos de 1960 e 1985, encontrou correlação negativa e estatisticamente significante entre aumento de gastos do governo e aumento do PIB per capita. Os resultados se devem aos efeitos negativos que o aumento de impostos gera ao sistema econômico. Para Barro (1991), o efeito do aumento de gastos e investimento em infraestrutura se deve, primariamente, ao tamanho do governo.

A análise de Barro (1991) é corroborada por Canning e Pedroni (2004) que, estudando o impacto de longo prazo do investimento em infraestrutura sobre a renda per capita, entre os anos de 1951 a 1992. Encontraram um nível ótimo de investimento em infraestrutura que maximiza o crescimento. Essa análise implica que, a partir de determinado nível de gasto governamental, é melhor o investimento em outros setores da economia.

Outro trabalho relevante para o entendimento da relação entre infraestrutura e crescimento foi o de Deverajan et al. (1996). Segundo os autores, não apenas a quantidade de recursos investidos em infraestrutura é importante, mas também a forma qualitativa do investimento. O estudo avaliou o impacto do gasto governamental corrente e gasto governamental em capital no crescimento econômico. A relação entre os gastos correntes do governo e a taxa de crescimento do produto foi positiva e estatisticamente significante. $\mathrm{O}$ resultado foi diferente quando se avaliou a relação entre o aumento de gasto em capital e o crescimento, nesse caso, houve insignificância estatística e relação negativa entre as variáveis.

O trabalho de Deverajan et al. (1996) se baseou fortemente em países em desenvolvimento, por isso os resultados foram controversos (Bertussi, Ellery, 2012). Quando os autores rodaram as mesmas regressões para 21 países desenvolvidos, o resultado foi exatamente o oposto. A relação entre gasto público corrente e crescimento do produto obteve coeficiente negativo e a relação entre gastos públicos em capital e crescimento do produto obteve coeficiente positivo. Segundo os autores o gasto público em capital é eficiente em países desenvolvidos, mas não em países em desenvolvimento. Os mesmos resultados também foram encontrados no trabalho de Ghosh e Gregoriou (2006), para uma amostra de 15 países.

Inspirados pelo modelo de Deverajan et al. (1996), Rocha e Giuberti (2005) estimaram a relação entre componentes do gasto governamental e a taxa de crescimento de longo prazo a nível estadual, entre os anos de 1986 e 2002. Como no modelo de Deverajan (1996), os dispêndios foram divididos entre gastos correntes e gastos com capital. Primeiramente, as autoras estimaram o impacto do gasto corrente e de capital para todos os estados, posteriormente, dividiram os estados em desenvolvidos (São Paulo, Rio de Janeiro, 
Minas Gerais, Rio Grande do Sul, Santa Catarina e Paraná) e em desenvolvimento (estados restantes).

Os resultados encontrados por Rocha e Giuberti (2005) diferem substancialmente do original. No trabalho, o impacto das despesas correntes na taxa de crescimento estadual é negativo e estatisticamente significante e a relação entre gastos públicos em capital e a taxa de crescimento estadual é positiva e estatisticamente significante. A conclusão encontrada rodando o modelo de forma agregada e desagregada foi a mesma.

Com resultado semelhante ao encontrado por Rocha e Giuberti (2005), Freitas, Castro Neto e Lôu (2009) avaliaram o efeito dos gastos do governo no crescimento da região Nordeste entre os anos de 1987 e 2006, utilizando dados em painel. No estudo, o coeficiente das despesas correntes foi negativo e estatisticamente significante, enquanto o coeficiente das despesas de capital obteve sinal positivo e estatisticamente significante.

Apesar de algumas divergências pontuais, há amplo consenso na literatura sobre o efeito dos gastos governamentais em infraestrutura, tanto na literatura internacional, quanto na brasileira. Além disso, como foi exposto, há aumento da produtividade do setor privado, redução da pobreza e redução da desigualdade nos países. O investimento em infraestrutura, portanto, é fundamental para o crescimento brasileiro no longo prazo, bem como essencial para suas aspirações econômicas e sociais. 


\section{2 - Análise do Setor Elétrico Brasileiro}

\subsection{Considerações Gerais sobre o Setor Elétrico}

O setor de energia vem sendo constantemente negligenciado pelo poder público. Entre os anos de 2001 e 2010, a média anual de investimento no setor elétrico era de apenas 0,67\% do Produto interno, pouco inferior à média do setor entre os anos de 1990 e 2000, 0,76\% . Com o baixo investimento, principalmente no final da década de 80 e início da década de 90 , tornou-se consenso a necessidade da mudança de paradigma no setor, com a mudança gradual no provedor de energia elétrica do setor público para o setor privado (Frischtak, 2012).

Apesar da pressão para a mudança no setor, o investimento privado enfrenta várias complicações. Em geral, os investimentos em energia são de grande magnitude, longo prazo, irreversíveis e intensivos em capital. Isso, somado à incerteza regulatória e ambiente macroeconômico instável, dificulta a mudança no setor. Torna-se, nesse sentido, imprescindível, a participação do governo para o provimento de energia de forma eficiente (Frischtak, 2012).

Segundo o IPEA (2012), os investimentos em energia necessitam, devido aos extensos prazos de amortização, de um sistema de planejamento, operação e regulação altamente sofisticado, o que dificulta ainda mais a operação do setor privado.

Outro problema é a deficiência do marco regulatório do setor elétrico, gerando diminuição dos investimentos públicos, insuficiência dos investimentos privados e esvaziamento do planejamento atual (Leite, 2007; IPEA, 2012). Ele é, em última instância, o responsável pelos gargalos no setor elétrico.

\subsection{Panorama Histórico do Setor Elétrico}

O surgimento da Lei n ${ }^{\circ} 8.631$ iniciou, em 1993, a reforma no setor elétrico (IPEA, 2012). A lei foi responsável por acabar com a tarifa única do setor, além disso, obrigava geradores e distribuidores a assinar contratos garantindo, assim, o suprimento de energia. Ainda em 1993, autorizou-se a criação de consórcios para a geração de energia, entre concessionárias e autoprodutores, com base no decreto $\mathrm{n}^{\circ} 915$.

Em 1995, com a Lei ${ }^{\circ}$ 9.074, criaram-se duas figuras importantes: a do Produtor Independente e a do Consumidor Livre. A partir desse momento, era permitido ao Produtor Independente vender energia elétrica proveniente de instalações de cogeração e ao Consumidor Livre comprar energia de qualquer fornecedor habilitado no mercado (IPEA, 2010). 
A despeito do início da reforma, ainda existiam vários gargalos na produção e distribuição de energia, o que demandava um novo marco regulatório para o setor. Por isso, entre 1996 e 1998 implantou-se o Projeto de Reestruturação do Setor Elétrico, estabelecendo o Novo Modelo Institucional do Setor Elétrico (NMISE) (IPEA, 2012).

Uma das principais mudanças feitas pelo NMISE foi a desverticalização das geradoras e transmissoras de energia, que estimulou a competição entre as empresas ao permitir sua participação em diferentes atividades dentro de uma cadeia produtora (Leite, 2007; IPEA, 2010 e 2012). Outra alteração, foi a mudança nos contratos de compra e venda de energia. Estes deveriam ocorrer no Mercado Atacadista de Energia Elétrica (MAE). E, para otimizar a operação do sistema elétrico, foi criado o Operador Nacional de Sistemas. Este mecanismo possibilitava comprar energia de termoelétricas, quando necessário (IPEA, 2010; IPEA, 2012).

Em 1996, a partir da Lei n ${ }^{\circ}$ 427, criou-se a Agência Nacional de Energia Elétrica (ANEEL) com o intuito de organizar e gerir licitações de aproveitamentos elétricos e de linhas de transmissão. Outra função da empresa era a de calcular o preço das tarifas praticadas pelo mercado, incluindo custos referentes à transmissão, distribuição e comercialização, além de servir como reguladora do setor.

Nesse sentido, a ANEEL é de fundamental importância devido à primordialidade da energia elétrica para o desenvolvimento da nação. É responsabilidade de ANEEL balancear a rentabilidade do setor, para que consiga sustentar o sistema energético, dando lucro, tanto aos investidores privados, quanto às geradoras e distribuidoras, com a necessidade de manter a tarifa a um preço acessível, possibilitando uma vantagem comparativa ao país (IPEA, 2012).

Todas as mudanças institucionais produzidas entre 1996 e 1998 visaram a produzir um ambiente institucional que facilitasse a entrada do ente privado, reduzindo riscos e aumentando investimentos. Segundo Montes e Reis (2011), as mudanças ocorridas no setor elétrico foram graduais, com prioridade para o setor de distribuição. A justificativa era de que seria mais difícil atrair o investidor sem um mercado atacadista de energia. Isso melhorou a eficiência do setor, aumentando a produtividade da mão de obra aplicada no setor e reduzindo as perdas elétricas (Tankha, 2009).

Posteriormente, o governo deu início a uma nova fase de privatizações. Para que se tornasse atrativa, incluiu empresas de geração da Eletrobrás e fez uma série de mudanças no setor como: demover a obrigatoriedade de construção de novos parques geradores, utilizar as receitas crescentes para reduzir débitos, melhorar o balanço da empresa reduzindo custos e esgotar as reservas (Tankha, 2009; IPEA, 2010 e 2012).

Porém, quando o governo preparava outra rodada de privatizações, tira-se a âncora 
cambial, desvalorizando o Real. Essa política impactou seriamente as empresas, que tinham grande parte de seus deveres em moeda estrangeira. $\mathrm{O}$ repentino aumento do endividamento das empresas de energia elétrica gerou um afastamento dos investidores. Isso fez com que, em 2000, grande parte da geração de energia elétrica permanecesse nas mãos do setor público (65\%) (Montes e Reis, 2011).

O efeito da retirada das âncoras foi potencializado pela contração fiscal realizada pelo governo no período. A despeito do aumento nos investimentos no setor de energia entre 1995 e 1998 (passou de 0,47\% do PIB para 0,89\% do PIB), em 2000 já se encontrava no patamar do período pré-reformas. $\mathrm{O}$ investimento privado era outro problema pois grande parte do valor investido era destinado à compra de ativos existentes e não à criação de novos (Tankha, 2009).

O governo também prejudicou as empresas do setor ao manter as tarifas baixas. Uma vez que a energia é insumo essencial e componente no preço de todas as mercadorias, o estado, com o intuito de controlar a inflação, era obrigado a controlar a tarifa, sacrificando os investimentos no setor em detrimento da política econômica. Isso só foi possível porque grande parte das empresas eram estatais (IPEA, 2012).

A redução inflacionária gerou um aumento de consumo energético generalizado. Entre 1996 e 2000, o aumento médio anual do consumo de energia foi de 4,8\%. Concomitante a isso, no final de 1999, os reservatórios brasileiros estavam em níveis preocupantes, com ocupação na região centro-oeste e sudeste em 19,7\% da capacidade. Havia, no final da década de 90, amplos indicativos de que o Brasil sofreria com uma crise energética, inclusive nos relatórios do BNDES (IPEA, 2012).

Em maio de 2001, após grave seca, o Operador Nacional do Sistema Elétrico (ONS) alertou o Governo Federal que as reservas hidroelétricas estavam praticamente esgotadas. Isso forçou o presidente Fernando Henrique Cardoso a declarar racionamento energético emergencial, visando a diminuir a demanda e, assim, evitando um "apagão". A redução de consumo no ano de 2001 foi de 7,9\%. A crise energética durou 10 meses e custou, pelo menos, US\$ 5 bilhões à indústria (IPEA,2012).

Após a crise energética de 2001, e com a mudança de presidente, outras reformas foram feitas. Admitindo que as privatizações não solucionaram os problemas de baixo investimento, o papel do estado, novamente, se tornou preponderante na manutenção do setor elétrico (Montes e Reis, 2011; Frischtak, 2013). Devido ao risco de racionamento, foi criado em 2002 o Comitê de Revitalização do Modelo do Setor Elétrico, responsável por reestruturar o setor elétrico do Brasil (IPEA, 2012).

Além deste Comitê, foi criada a Empresa de Pesquisa Energética (EPE), com o objetivo 
de planejar a oferta e as diretrizes do setor energético no longo prazo, e o Comitê de Monitoramento do Setor Elétrico (CMSE), responsável por acompanhar o desempenho das empresas e mensurar a demanda energética (IPEA, 2010; IPEA, 2012).

Ocorreu, também, uma mudança na comercialização da energia elétrica, com a criação de um sistema contratual bilateral entre geradores e distribuidores, gerando uma tarifa única em cada submercado. Também foi feita uma diferenciação entre energia velha (centrais com contratos anteriores a 2001) e energia nova (centrais com contratos posteriores a 2001), para impedir que o preço da energia contratada convirja para o custo de expansão do parque gerador (IPEA, 2010).

\subsection{Atual Situação do Setor Elétrico}

O investimento no setor elétrico por parte do governo brasileiro é essencial. Entre 1990 e 2012, houve aumento anual médio de 3,19\% no consumo de energia. Durante todo o período de análise, apenas em 2001 e 2009 observou-se retração. No entanto, nesses dois anos, a diminuição no consumo foi afetada por fatores exógenos, não refletindo uma diminuição genuína na demanda. Em 2001, foi devido à crise energética brasileira, e, em 2009, à retração econômica derivada da crise mundial de 2008 (IPEA, 2012).

Um dos efeitos do baixo investimento no setor foi a crise vivida em 2014. O problema começa em 2013, quando o Brasil decide baixar a tarifa de energia através da MP 579, sem, no entanto, baixar os custos de transmissão e transmissão de energia. Os custos elevados e as baixas tarifas acabaram por estrangular as transmissões de energia. Além disso, o Brasil, em 2013, sofreu secas intensas, obrigando as geradoras a recorrer ao sistema termoelétrico. Segundo Ildo Luis Sauer (2015), caso o Brasil obtivesse taxa de crescimento semelhante à de anos anteriores, a segurança do setor elétrico estaria comprometida. Apagões, durante fevereiro de 2014, chegaram a comprometer $7 \%$ do consumo nacional.

A MP 579 gerou grande prejuízo às transmissoras e geradoras, a capacidade de expansão e aumento da qualidade da malha elétrica ficaram comprometidas devido à deteriorada saúde financeira das empresas do setor elétrico. O governo federal baixou a tarifa de energia em $20 \%$, em contrapartida renovou as concessões das empresas de energia. No entanto, a política do governo sofreu com a não aceitação dos contratos por parte da Cesp (São Paulo), Cemig (Minas Gerais) e Copel (Paraná). Além disso, durante o ano de 2013, houve forte seca no Brasil, obrigando as empresas elétricas a comprarem energia de geradoras termoelétricas, com preço mais alto. Sem caixa para manter os investimentos prometidos e sofrendo grande pressão por parte das geradoras e transmissoras, o governo foi obrigado a 
aumentar a tarifa de energia para patamares anteriores aos da MP 579. A atitude de diminuir em 20\% a tarifa mergulhou o Brasil numa crise do Setor Elétrico, gerando insegurança no abastecimento e destruindo o caixa das empresas do setor (Sauer, 2015).

O maior demandante de energia elétrica é o setor industrial, compondo $38 \%$ de participação no consumo final de energia elétrica, seguido pelo setor de transportes, com 33\%, e pelo setor residencial, com 10\% de participação. Estima-se que, em 2020, a demanda energética do Brasil será de 372 milhões de tep (tonelada equivalente de petróleo), com a indústria e transportes sendo os principais demandantes, com $67 \%$ de participação.

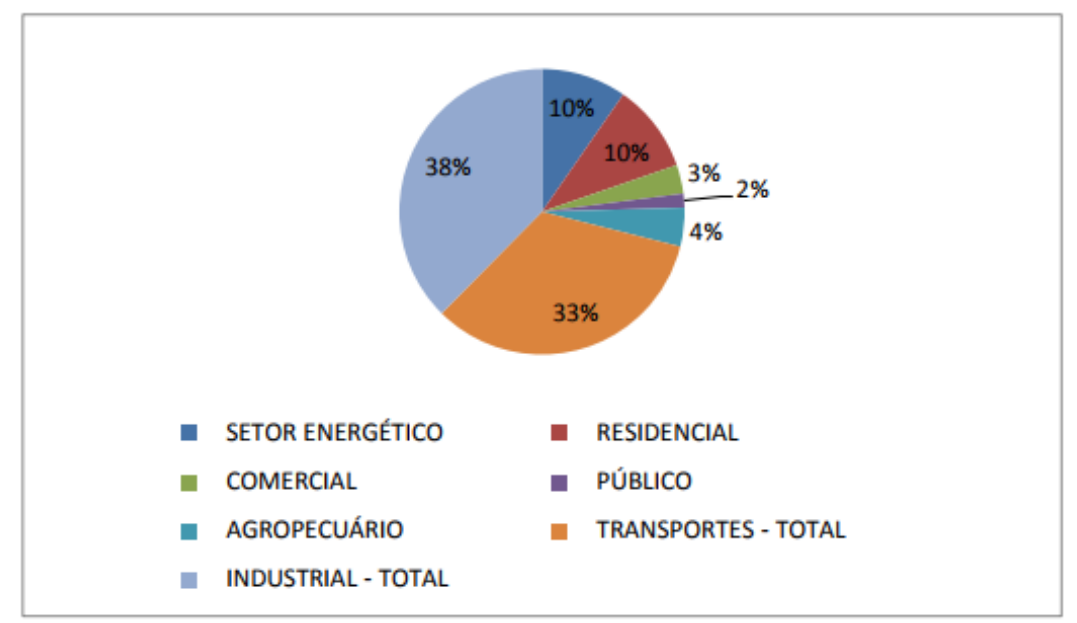

Gráfico 1: Participação no consumo final energético por setor em 2012.

Fonte: Balanço Energético Nacional.

Wolfram et al. (2012) indicam que o uso de energia elétrica por parte das regiões vem mudando ao longo do tempo. Apesar de continuar como maior demandante de energia, a região sudeste perdeu participação relativa. No ano de 2004 , correspondia a $54,89 \%$ do consumo de energia elétrica brasileiro, já no ano de 2012, baixou para 52,49. Entre os anos de 2004 e 2012, o Centro-Oeste aumentou 17 pontos percentuais, enquanto o Nordeste aumentou 8 pontos percentuais. $\mathrm{O}$ fenômeno se deve, principalmente, segundo a ANEEL, ao aumento de renda e maior alcance de programas sociais, como o Luz para todos.

A oferta energética do Brasil se destaca por sua variedade de fontes, utilizando, de forma equilibrada, fontes renováveis e não renováveis. Cerca de 43,5\% da energia utilizada pelo Brasil é de fonte renovável, desta se destacam: biomassa de cana (17,5\%), hidráulica $(12,6 \%)$, lenha e carvão vegetal (8\%). Quanto às energias não renováveis se destacam: petróleo e derivados (36,5\%), gás natural (12,3\%), carvão mineral (5,5\%) e urânio (1,5\%) (EPE, 2017).

A produção de energia elétrica é majoritariamente composta pela geração hidroelétrica, responsável por $68,1 \%$ do total, com destaque também para: biomassa $(8,2 \%)$, eólica $(5,4 \%)$ e gás natural $(9,1 \%)$ (EPE, 2017). Além da vantagem por ser uma fonte renovável, 
a energia derivada de hidroelétricas, também tem custos operacionais pequenos, o que dá vantagens comparativas ao Brasil (CNI, 2012).

Por se tratar de uma fonte energética majoritariamente localizada na região norte, portanto, longe dos grandes centros, a energia provida por fontes hidráulicas apresenta desafios logísticos ao Brasil. Além disso, possui custos de investimento iniciais altos e grandes prazos de execução, por isso a oferta de eletricidade no Brasil é provida, em grande parte, por empresas estatais (67\%), sendo a maior parte destas controladas pelo governo federal (23\%)- IPEA, 2012.

A tarifa de energia cobrada pela Agência Nacional de Energia Elétrica (ANEEL), segundo estimativas do Instituto Acende Brasil, possui a seguinte estrutura: $45 \%$ se destina a tributos e encargos, $24 \%$ são destinados às distribuidoras e $31 \%$ são destinados às geradoras. A estrutura de encargos se reflete diretamente na competitividade brasileira. O IPEA (2010) considera a quantidade de encargos e tributos preocupante, já que uma energia barata é imprescindível à produção com preços competitivos.

Recentemente, o Setor Elétrico Brasileiro sofreu grandes dificuldades, tanto em carência de investimentos, quanto em relação a diminuição de tarifas abaixo do que era aconselhável. Esses dois fatores geraram uma crise no setor, que gerou aumentos nas tarifas, trazendo grande prejuízo para a economia brasileira.

As dificuldades enfrentadas pelo Brasil no Setor Elétrico evidenciam a necessidade de acompanhamento e investimento, principalmente do setor público. A mensuração e estudo de políticas para o setor são de fundamental importância, não só para a melhora da qualidade de vida dos brasileiros, mas para a maior competitividade da economia. 


\section{3- Análise sobre o Setor de Saneamento no Brasil}

\subsection{Considerações Gerais sobre o Setor de Saneamento Básico}

A definição de saneamento é: abastecimento de água, esgotamento sanitário (coleta e tratamento), manejo de resíduos sólidos e drenagem de águas pluviais (Saiani, et al, 2013). O entendimento é o utilizado na Lei $\mathrm{n}^{\circ} 11.445 / 2007$, que estabelece as diretrizes para o setor.

O investimento em saneamento é essencial para a prevenção de doenças. A reversão de recursos para o setor melhora a produtividade da população e poupa recursos do estado, liberando investimentos para outros setores. Áreas com esgoto a céu aberto são propícias para mosquitos e parasitas, contaminando a população e aumentando gastos hospitalares por parte do governo (Mcgranahan, 2015).

Quando se avalia países em desenvolvimento, infecções intestinais são uma das maiores causas de óbito para crianças abaixo de 5 anos, correspondendo a $20 \%$ das mortes (Rasella, 2013). Além disso, a universalização dos serviços ocasionaria na diminuição de internações por diarreia grave em 25\%, passando de 462 mil casos para 343 mil casos, bem como redução no número de óbitos, em $65 \%$. Apenas a redução do número de internações faria o governo economizar 42 milhões por ano (FGV/Trata Brasil, 2010).

Segundo a Fundação Getúlio Vargas, em parceria com o Instituto Trata Brasil, em 2010, indivíduos com acesso a saneamento básico possuem 6,5\% chance menor de faltar ao trabalho por qualquer motivo. O afastamento por diarreia é $19,2 \%$ menor. A expansão da estrutura em saneamento poderia representar economia de $\mathrm{R} \$ 309$ milhões por ano apenas com faltas (FGV/Trata Brasil, 2010).

A estimação do aumento da infraestrutura em relação a produtividade e a renda foi ainda mais impactante. Obtendo acesso à uma boa estrutura de esgoto e saneamento, a produtividade aumenta cerca de 13,3 pontos percentuais. A universalização dos serviços aumentaria a massa de salários em 3,8\%, gerando acréscimo na folha total de R $\$ 41,5$ bilhões, além de gerar 120 mil postos de trabalho apenas no setor de turismo (FGV/Trata Brasil, 2010).

Para mensurar a importância na reversão de recursos para a infraestrutura brasileira, Silva e Trinches (2014) avaliaram o impacto do aumento de 1\% nas despesas com saúde e saneamento em relação ao produto interno do país. Encontraram que, ao aumentar 1\%, o impacto seria de $0,12 \%$ no produto.

Avaliando o impacto do Programa Água para Todos no estado da Bahia, Rasella (2013) estimou que o aumento de cobertura do programa em 1\% geraria redução nas mortes por infecções gastrointestinais na ordem de $0,52 \%$, em crianças menores de 5 anos. Além disso, 
constatou que, em municípios com cobertura do programa maior que $10 \%$, havia uma redução nas mortes por diarreia em 39\%, com diminuição de 6\% nas internações hospitalares.

Apesar da importância do saneamento na qualidade de vida e produtividade da população, ele não é valorado como outros setores. Saúde, educação e segurança possuem reversões de investimento consideravelmente maiores, embora haja relação direta entre o saneamento e essas categorias.

Um dos estudos que apontam a relação direta entre investimentos em saneamento e impacto na educação é o de Scriptore et al (2015). Utilizando dados do Instituto Brasileiro de Geografia e Estatística (IBGE), Sistema Nacional de Informações sobre Saneamento (SNIS), Ministério da Saúde e Censo escolar, encontraram que, ao aumentar o número de pessoas com acesso à água e ao esgoto em $1 \%$, há um aumento na frequência escolar em $0,11 \%$, redução no abandono escolar em $0,49 \%$ e uma diminuição na distorção idade-série na ordem de $0,96 \%$.

A explicação para isso, segundo Scriptore et al. (2015) é que, ao ter contato com condições insalubres, parasitas e doenças tem-se também maior probabilidade de comprometimento das faculdades cognitivas.

Além de prejudicar várias facetas do desenvolvimento social, o parco investimento em saneamento contamina lençóis freáticos e contribui para o assoreamento dos rios (Saiani et al. 2013). Esse investimento se torna ainda mais relevante quando se avalia o desenvolvimento na economia e os resíduos sobressalentes. O crescimento econômico, se acompanhado de manutenção dos níveis prévios de infraestrutura em saneamento, gera déficits cada vez maiores na conservação do meio ambiente (Saiani et al. 2013).

Nascimento Júnior e Freire (2011) buscaram mensurar os danos ambientais decorrentes do despejo inadequado de esgoto. Encontraram que os prejuízos ambientais gerados, apenas entre 2000 e 2008, estão na casa de R \$24 bilhões por ano. Concomitantemente, o investimento em recursos hídricos foi de $\mathrm{R} \$ 304$ milhões.

\subsection{Panorama Histórico do Setor de Saneamento Básico}

Em estudo recente, o Instituto Trata Brasil, em parceria com o Conselho Empresarial Brasileiro, estimou que o Brasil está em $112^{\circ}$ num ranking de 200 países em termos de infraestrutura de saneamento. O IBGE, num estudo de 2008, estimou que 44,8\% das cidades não possuíam rede coletora de esgoto (2.495 no total). Dados do Ministérios das Cidades, em 2011, estimam que 36 milhões de brasileiros não possuíam água tratada e 48,1\% da população não possuía acesso à coleta de esgoto. 
No entanto, o histórico de descaso e falta de investimentos em saneamento remete à república velha. Até 1930 não existia qualquer regulação do setor no Brasil, sendo que as empresas operantes no mercado eram parte estatais, parte privadas e parte estrangeiras, não havendo subsídios e com as tarifas cobradas superando os custos na ordem de 7\% (EBAP/FGV, 1995).

A primeira tentativa de regulação do setor data de 1934, com a instituição do Código de Águas. Nele, havia o estabelecimento de um sistema híbrido entre concessões e regulação estatal. No período, o investimento em saneamento se encontrava em âmbito municipal. Apenas em 1950, a situação se altera e a gestão passa a ser feita por empresas estaduais, através de concessões (Brito, 2001).

Após 1964, a gestão do saneamento foi caracterizada por centralização dos serviços. Destaca-se, nesse período, o esforço do governo para melhorar a situação sanitária no país. Em 1968, cria-se o Sistema Financeiro de Saneamento (SFS) e, em 1971, implanta-se o Plano Nacional de Saneamento (Planasa). Esse plano tinha como principais objetivos: aumentar a cobertura de serviços de abastecimento e coleta de esgoto, instituir política tarifária baseada em valores reais e concentrar a prestação de serviços em empresas estaduais (Faria e Faria, 2004).

Para melhorar a infraestrutura em saneamento no Brasil, o Planasa concedia incentivo à criação de 27 empresas estaduais de saneamento, com amplos poderes e relativa independência, sendo responsáveis por decisões estratégicas e tecnológicas (Sousa e Costa, 2013). As tarifas para o período deveriam buscar: auto sustentação das companhias estaduais de saneamento, adequação das tarifas ao poder aquisitivo da população, remunerar anualmente $12 \%$ sobre o investimento, regular as tarifas pelo custo do serviço (Pedrosa, 2001).

O Planasa representou o auge dos investimentos em saneamento no Brasil. Entre 1971 e 1980, 0,46\% do produto interno brasileiro, na média, eram investidos em saneamento (Saiani e Toneto, 2010). Se o investimento no setor tivesse se mantido, atualmente teríamos universalização dos serviços de coleta de esgoto e fornecimento de água (Saiani e Toneto, 2010).

Entre 1970 e 2000, houve uma elevação na proporção de domicílios que continham acesso à água e ao esgoto. Sendo que o aumento principal ocorreu na década de 70 . No começo dessa década, apenas 35\% dos domicílios possuíam acesso à água encanada e 15\% possuía acesso à rede de esgoto. Ao final da década, 55\% dos domicílios continham acesso à água e $29 \%$ à rede de esgoto (Saiani e Toneto, 2010).

Em 1978, o regime tarifário é, novamente, alterado através da Lei $\mathrm{n}^{\circ} 6.528$. Cabia ao regime tarifário buscar o equilíbrio entre bem-estar da população e saúde financeira 
das empresas de saneamento estaduais. As alterações foram: normas gerais de tarifação e responsabilidade de fiscalização cabem, a partir desse momento, ao Ministério do Interior, cabem ao governo estadual a proposição e estudo sobre tarifas, que serão submetidos ao Ministério do Interior e, posteriormente, ao Conselho Interministerial de Preços (CIP) (Pedrosa, 2001).

Ao longo da década de 80 , com a inflação inercial se tornando o principal vilão econômico, e com esforços redobrados para controlá-la, foi-se gradualmente primando pelo lado social e econômico do baixo preço tarifário, em detrimento da saúde financeira das empresas estaduais de saneamento. As tarifas foram, sistematicamente, ajustadas abaixo dos índices, muitas vezes sequer cobrindo o custo operacional. Com os balanços seriamente prejudicados e risco de falência geral, a partir de 1991, as concessionárias voltaram a ter liberdade tarifária, com a posterior extinção do Planasa, em 1992 (Pedrosa, 2001).

Em consequência dos esforços do governo em conter a inflação e problemas em sanar as contas públicas, continuamente em déficit, a década de 80 sofreu uma grande redução na taxa de ampliação dos serviços, em contraste com a década de 70. Segundo dados de Saiani e Toneto (2010), a taxa de crescimento do acesso à água entre 1970 e 1980 foi de 65,87\%, enquanto entre 1980 e 1990, a ampliação do serviço foi de apenas 30,15\%. A variação do acesso ao esgoto foi ainda maior, entre 1970 e 1980, o aumento do acesso ao serviço foi de 111,11\%, enquanto a ampliação entre 1980 e 1990 foi de $28,97 \%$.

A década de 90 também enfrentou dificuldades no setor, a evolução da ampliação dos serviços de acesso à água se reduziu drasticamente, passando de 30,15\% para 8,97\%. O acesso ao esgoto teve resultado melhor, a ampliação do serviço foi de $41,69 \%$ no período (Saiani e Toneto, 2010). As dificuldades financeiras enfrentadas pelo governo à época e a carência no provimento dos serviços públicos e de infraestrutura levaram o governo a buscar alternativas.

Com o arroxo fiscal da década de 90, principalmente após o Plano Real, e a tentativa de reduzir o papel do estado no provimento de serviços, é promulgada a Lei $n^{\circ} 8.987$, conhecida como Lei de Concessões. Esta mudança gera um novo paradigma no setor, primando-se pela busca de um novo papel para o Estado (Faria e Faria, 2004).

Apesar de grande esforço de privatização por parte do governo federal, a década de 90 foi marcada por grande resistência dos estados e municípios que, apesar de divergências históricas, se juntaram para barrar o novo modelo que vinha se estabelecendo (Sousa e Costa, 2013).

Mesmo com problemas inflacionários e de orçamento, é necessário ressaltar o 
avanço brasileiro no setor de infraestrutura em saneamento entre os anos de 1980 e 2000 . Houve, nesse período, aumento na proporção de municípios atendidos por serviços de abastecimento de água em todas as faixas de renda, enquanto que, no caso da coleta de esgoto, apenas municípios com maior e menor faixas de renda obtiveram avanços (Saiani e Toneto, 2010).

As tentativas de privatização do setor foram reascendidas em 2004 com a aprovação da Lei $\mathrm{n}^{\circ}$ 11.079, legislando sobre as Parcerias Público-Privadas (PPP). Outra tentativa foi feita em 2005, com a Lei $\mathrm{n}^{\circ} 11.107$ regulamentando a atuação dos consórcios públicos. Os consórcios são de grande valia para o governo pois possibilitam a prestação de serviços que ultrapassam a fronteira de um único município, além de promover economias de escopo e regular a relação entre serviços municipais e estaduais (Heller, 2009).

Outra tentativa de mudar a estrutura do Setor foi a imposição do marco regulatório, em 2007. O grande avanço da promulgação da lei foi que, a partir dela, os operadores são obrigados a manter transparência contábil, possibilitando a sistematização dos dados e de políticas (Cunha, 2011). Apesar de muito importante, o marco regulatório do setor sofreu rejeição devido à forte influência das empresas estaduais de saneamento, tendo poucas determinações postas em prática (Melo e Galvão Júnior, 2013).

Falta hoje um ente regulador que, a nível nacional, seja eficiente. Os organismos atuais a nível municipal e estadual são ineficientes e incipientes, diante das grandes empresas de saneamento brasileiras (Nunes, 2015). Outro problema é a polarização de interesses no setor entre estados e municípios, tornando inviável a decisão sobre pontos importantes da expansão do setor. De um lado, as companhias estaduais buscam manter a estrutura de governança instituída pela Planasa, do outro, os municípios querem mais autonomia nas decisões e imposição de tarifas (Sousa e Costa, 2013).

\subsection{Atual Situação do Setor de Saneamento Básico}

Não há muitos incentivos políticos para o investimento em saneamento. Reverter investimentos para políticas de curto prazo e consideradas socialmente mais importantes (como saúde, educação e segurança), geram um capital político maior, dão maior visibilidade e atraem mais atenção (Winters e Karim, 2014). Grande parte das obras de saneamento foram feitas por fatores econômicos e não sociais (Saiani, 2006).

No início dos anos 2000, estabeleceu-se a meta de, em 2020, obter universalização dos serviços de saneamento. Para que o objetivo fosse cumprido, dever-se-ia investir $0,45 \%$ do 
Pib anualmente. Porém, o investimento feito entre 2000 e 2005 ficou na casa de $0,2 \%$ ao ano.

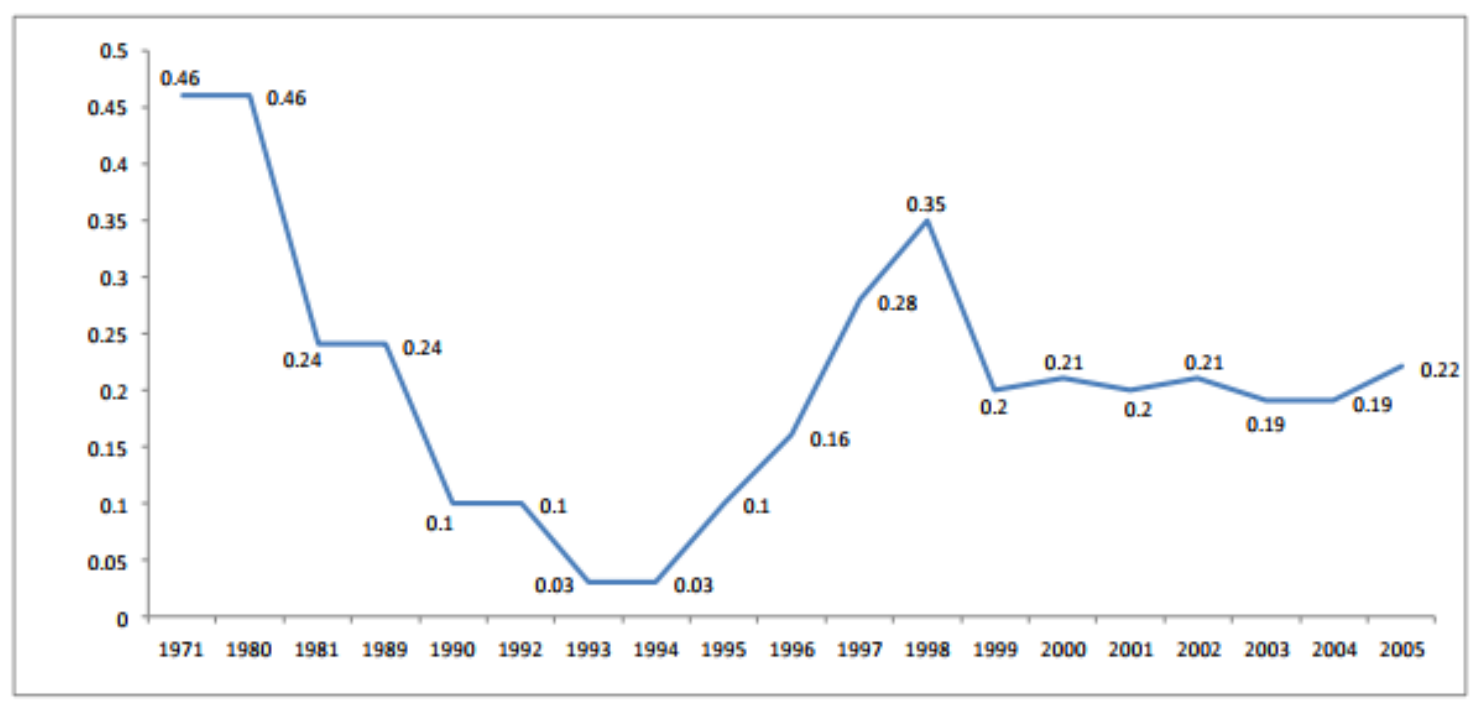

Gráfico 2: Investimentos em saneamento básico (\% PIB) no Brasil, de 1970 a 2005.

Fonte: Saiani e Toneto Júnior (2010).

Entre 2005 e 2009, foram disponibilizados $\mathrm{R} \$ 40,2$ bilhões em recursos não onerosos para se investir em saneamento, dos quais $\mathrm{R} \$ 28,3$ bilhões foram de fato investidos. No mesmo período, foram contratados $\mathrm{R} \$ 15$ bilhões em recursos do FGTS e $\mathrm{R} \$ 11,9$ bilhões em recursos do Banco Nacional de Desenvolvimento (BNDES), dos quais foram gastos R $\$ 6,1$ bilhões por parte do FGTS e 4,4 bilhões por parte do BNDES (Borja, 2011). Cabe ressaltar a diferença entre recursos onerosos e não onerosos. Os recursos onerosos são os que cobram encargos financeiros e juros, os não onerosos os que não cobram.

Ao perceber a impossibilidade do cumprimento da meta até 2020, o plano atual do setor de saneamento foi postergado em 13 anos. Para atingir a universalização dos serviços de saneamento até lá, segundo o Plano Nacional de Saneamento Básico (Plansab), do Ministério das Cidades em 2014, é necessário investimento de R $\$ 304$ bilhões, divididos em 20 anos, dos quais, grande parte será de responsabilidade governamental. Atualmente, menos de $5 \%$ dos serviços ofertados são feitos por empresas privadas.

A partir de 2006, houve crescimento dos índices absolutos de investimento em saneamento no Brasil, sem, no entanto, serem acompanhados pelos índices relativos. Em 2006, o investimento total foi na ordem de $\mathrm{R} \$ 4,5$ bilhões, correspondendo a $0,19 \%$ do produto interno no período, enquanto isso, em 2014 , o total foi de $\mathrm{R} \$ 12,2$ bilhões, correspondendo a $0,22 \%$ do Pib no período, segundo o Sistema Nacional de Informações sobre Saneamento (SNIS). 


\begin{tabular}{|c|c|}
\hline Ano & $\begin{array}{c}\text { Investimento realizado } \\
\text { (RS milhões) }\end{array}$ \\
\hline 2006 & $4.537,4$ \\
\hline 2007 & $4.237,8$ \\
\hline 2008 & $5.620,3$ \\
\hline 2009 & $7.844,2$ \\
\hline 2010 & $8.962,3$ \\
\hline 2011 & $8.378,3$ \\
\hline 2012 & $9.753,70$ \\
\hline 2013 & $10.485,2$ \\
\hline 2014 & $12.197,7$ \\
\hline
\end{tabular}

Tabela 1: Investimento realizado no setor de saneamento básico em milhões de reais.

Fonte: SNIS (2006 A 2014).

O Brasil apresenta vasta necessidade de investimento no setor de saneamento básico, porém, a demanda por infraestrutura varia amplamente entre as regiões. A região Norte é a que precisa de mais investimentos, cerca de $\mathrm{R} \$ 641$ per capita, seguido pela região CentroOeste, com $\mathrm{R} \$ 543$ per capita, da região Sul, $\mathrm{R} \$ 481$ per capita, da região Nordeste $\mathrm{R} \$ 395$ per capita e da região Sudeste com $\mathrm{R} \$ 358$ per capita, segundo Leoneti et al. (2011).

A região sudeste é a que apresenta melhores índices de abastecimento de água (91,7\% da população é atendida), coleta de esgoto (78,3\% da população é atendida), deixando a desejar apenas no tratamento do esgoto, com menos de $50 \%$ do esgoto sendo tratado. Os dados diferem fortemente do que é encontrado na região Norte. Os índices de abastecimento de águas, coleta e tratamento de esgoto são respectivamente: 54,5\%, 7,9\% e 14,4\% (SNIS, 2014).

Para as outras regiões temos:

\begin{tabular}{|c|c|c|c|}
\hline \multirow[b]{2}{*}{ Região } & \multicolumn{2}{|c|}{ Índice de atendimento com rede (\%) } & \multirow{2}{*}{$\begin{array}{c}\text { Índice de } \\
\text { tratamento do } \\
\text { esgoto gerado }(\%)\end{array}$} \\
\hline & Água & Coleta de esgoto & \\
\hline Norte & 54,5 & 7,9 & 14,4 \\
\hline Nordeste & 72,9 & 23,8 & 31,4 \\
\hline Sudeste & 91,7 & 78,3 & 45,7 \\
\hline Sul & 88,2 & 38,1 & 36,9 \\
\hline Centro-Oeste & 88,9 & 46,9 & 46,4 \\
\hline Brasil & 83,0 & 49,8 & 40,8 \\
\hline
\end{tabular}

Tabela 2: Nível de atendimento com rede de abastecimento de água, de coleta de esgoto e de tratamento de esgoto gerado por região do Brasil, no ano de 2014.

Fonte: SNIS (2014).

É possível observar que a própria estrutura de serviços de saneamento brasileiro é desigual, enquanto o abastecimento de água encontra-se num nível muito mais próximo à universalização, a coleta e tratamento de esgoto estão em níveis bastante inferiores. No entanto, 
os dois se encontram em lados opostos da mesma moeda. Investir apenas na universalização do abastecimento de água sem, ao mesmo tempo, investir na coleta e tratamento de esgoto implica onerosos custos de tratamento, na medida que o esgoto contamina nascentes e o lençol freático.

Divergindo do estudo do Instituto Trata Brasil, em parceria com o Conselho Empresarial Brasileiro, que classificou o Brasil em $112^{\circ}$ num ranking de 200 países em termos de infraestrutura de saneamento, a World Health Organization (WHO) colocou o país à frente de todos os outros países do BRICS (Brasil, Rússia, índia, China e África do Sul) e de vários países da América Latina (Peru, Bolívia, Guatemala e Colômbia) em termos de acesso a condições sanitárias adequadas. No entanto, atrás de Argentina, Cuba, Chile, Equador, México e Uruguai. O estudo afirma que $15 \%$ da população brasileira se encontra em situação sanitária precária, enquanto $4 \%$ da população não encontra qualquer tipo de estrutura, sendo obrigada a defecar a céu aberto.

A infraestrutura de saneamento brasileira é, majoritariamente, financiada pelo regime tarifário e, minoritariamente, mediante orçamento federal (Cunha, 2011). Observando o baixo investimento no setor, é possível inferir que a estrutura tarifária vigente encontra dificuldades sistemáticas em arrecadar recursos que possibilitem a expansão da estrutura presente.

Grande parte do entendimento sobre a atual situação do setor de infraestrutura de saneamento no Brasil passa por como esse mercado se financia. Por isso, cabe analisar a estrutura tarifária das empresas estaduais, principais responsáveis pelo provimento do serviço no Brasil.

As tarifas cobradas pelas empresas estaduais variam muito entre si dependendo de fatores como: aspectos técnicos e econômicos, nível de renda dos consumidores e exigência sobre a qualidade do serviço. No entanto, existem algumas similaridades entre as empresas estaduais do setor. As tarifas são cobradas de forma diferente dependendo do setor de análise, existem preços diferentes para o setor residencial, comercial, industrial e público.

As tarifas também se alteram de acordo com faixas de consumo, sendo mais elevadas de acordo com o uso da energia. Isso é feito para desestimular o consumo excessivo. Outra semelhança entre as empresas estaduais de saneamento, é a diminuição da tarifa para setores de renda mais baixos e estabelecimentos comerciais pequenos. A diferença de tarifa cobrada entre diferentes faixas de renda evidencia o aspecto social do provimento do serviço de saneamento.

É importante ressaltar que há grandes diferenças entre os preços cobrados pelas companhias estatais de saneamento. Isso é resultado da independência entre elas, decorrente do 
Planasa, onde as empresas estatais tinham autonomia para pleitear a tarifa que desejassem, obtendo posterior permissão para aplicá-la ou não.

No caso do abastecimento de água no setor residencial, há uma variação de quase 6 mil por cento no valor do metro cúbico de água ofertado, variação entre a tarifa social cobrada pela $\operatorname{Copasa}^{1}\left(\mathrm{R} \$ 0,44 / \mathrm{m}^{3}\right)$ e o valor cobrado pela $\operatorname{Deso}^{2}\left(\mathrm{R} \$ 26,22 / \mathrm{m}^{3}\right)$.

A discrepância na tarifa cobrada também é evidente na indústria, comércio e setor público com diferenças de respectivamente: 383\% (diferença entre a tarifa cobrada pela Cosama $^{3}, \mathrm{R} \$ 4,49 / \mathrm{m}^{3}$, e a tarifa cobrada pela Embasa ${ }^{4}, \mathrm{R} \$ 17,23 / \mathrm{m}^{3}$ ); $493 \%$ (diferença entre a tarifa cobrada pela Cosama, $\mathrm{R} \$ 3,49 / \mathrm{m}^{3}$, e a tarifa cobrada pela Embasa, $\left.\mathrm{R} \$ 17,23 / \mathrm{m}^{3}\right) ; 414 \%$ (diferença entre a tarifa cobrada pela Cosama, $\mathrm{R} \$ 4,43 / \mathrm{m}^{3}$, e a tarifa cobrada pela Deso, $\left.\mathrm{R} \$ 18,36 / \mathrm{m}^{3}\right)$.

O preço das tarifas de esgoto é, em geral, mais baixo do que as de abastecimento de água. O motivo para isso é que o número de domicílios atendidos pelo serviço de esgoto é consideravelmente menor que os atendidos pelo de água. Como no caso do abastecimento de água, há grande variação nos valores cobrados e diminuição dos valores para extratos de renda mais baixos da população. O menor valor cobrado foi $\mathrm{R} \$ 0,44 / \mathrm{m}^{3}$ (categoria residencial social da $S a n e p a r{ }^{5}$ ) e o maior valor cobrado foi $\mathrm{R} \$ 16,71 / \mathrm{m}^{3}$ (categoria industrial da Cedae ${ }^{6}$ ).

Em decorrência do que foi apresentado nesse capítulo, é possível perceber que, apesar da importância do setor, a infraestrutura em saneamento no Brasil está sendo negligenciada. Há uma desigualdade muito grande entre as regiões nacionais com relação ao acesso à infraestrutura em saneamento e uma discrepância muito grande nos regimes tarifários, sendo que muitas empresas não geram o suficiente para a ampliação dos serviços.

O Brasil precisa avançar muito para atingir a universalização dos serviços. Para isso, é necessário um esforço conjunto de governo federal, estados e municípios, com estudos sérios e avaliação de políticas. Há grande necessidade de comprometimento por parte do governo em relação a se investir o que foi planejado.

\footnotetext{
${ }^{1}$ Companhia de Saneamento de Minas Gerais.

${ }^{2}$ Companhia de Saneamento de Sergipe.

${ }^{3}$ Companhia de Saneamento do Amazonas.

${ }^{4}$ Empresa Baiana de Águas e Saneamento.

${ }^{5}$ Companhia de Saneamento do Paraná.

${ }^{6}$ Companhia Estadual de Águas e Esgotos do Rio de Janeiro.
} 


\section{4-Avaliação sobre os Impactos e Investimentos Realizados pelo Programa de Aceleração do Crescimento (PAC)}

\subsection{Considerações Gerais sobre o Programa}

A despeito da importância, vários entraves se apresentam em relação à reversão de capital para setores estruturais no Brasil. O primeiro entrave é a corrupção. O Brasil está em $79^{\circ}$ lugar em percepção de corrupção, num estudo divulgado pela Transparência Internacional em 2016. O país fica atrás de países como: Botswana (35), Namíbia (53), Senegal (64) e Gana (70). Escândalos recentes como o do Mensalão e a operação lava-jato contribuem ainda mais para o ceticismo empresarial brasileiro.

O segundo fator é a diferença de retorno do capital investido entre as diversas regiões do país. É comum não haver interesse empresarial quando o custo de oportunidade da aplicação é o investimento em partes mais lucrativas do território nacional. Esse fator dificulta a reversão de investimentos de forma adequada, gerando escassez na oferta de serviços e, posteriormente, sobre preço na execução das obras.

Uma saída seria a admissão de empresas internacionais para a prestação dos serviços. No entanto, a instabilidade macroeconômica recente diminui a disponibilidade do investimento. Segundo o site do Banco Central, em janeiro de 2010 o dólar chegou ao valor mínimo de $\mathrm{R} \$ 1,72$, já em setembro de 2015 o dólar chegou ao valor máximo de $\mathrm{R} \$ 4,24$. A variação em 5 anos foi de $246 \%$, tornando impraticável a avaliação de longo prazo por parte das empresas e obrigando-as a cobrar um sobrepreço no valor do serviço, de tal forma que o valor cobrado suplantasse o risco a longo prazo do país.

Um estudo publicado pela FGV em 2006, em parceria com a União Nacional da Construção, mostra a carência de investimentos brasileiros em infraestrutura. O Brasil fica atrás de Namíbia, Estônia e Hungria no que se refere à extensão da malha rodoviária, por exemplo. Quando o país é comparado a países como China e Coréia do Sul, a diferença é ainda mais abismal. Segundo Frischtak (2008), para alcançar os dois países, seria necessário um investimento anual de $4 \%$ a $6 \%$ do PIB durante 20 anos. O investimento presente não é sequer suficiente para manter o estoque atual, a quantidade necessária é 3\%, mas em 2007 foi de apenas $2,01 \%$, entre 2008-14 a média foi pouco superior, $2,18 \%$.

Durante a década de 80, a taxa de investimento do Brasil em porcentagem do PIB se encontrava na faixa de 5\% (Frischtak, 2008). Esse valor fazia com que o Brasil fosse o país com maior taxa de investimento da América do Sul. No entanto, quando os planos econômicos (Cruzado, Cruzado II, Collor, Bresser, Verão, Arroz com Feijão) foram implantados, ajustes 
ficais essenciais ao sucesso dos planos minaram os investimentos nos setores de infraestrutura. Com isso, os investimentos variaram entre $2 \%$ e $4 \%$ do PIB até meados da década de 90 (Frischtak, 2008). Posteriormente, o plano real reduziu ainda mais a taxa de investimento, fazendo com que variassem entre $1,8 \%$ e 2,8\% do PIB (Silva e Fortunato, 2007).

A redução de investimentos ocorrida na década de 80 fez com que o país fosse ultrapassado pelo Chile e pela Colômbia. Essa diferença aumentou durante a década de 90 . Em 2001, os dois países possuíam investimentos em infraestrutura superiores ao dobro da taxa encontrada no Brasil (Frischtak, 2008).

Para reduzir o abismo de investimento entre o Brasil e outros países, em 2007 foi criado o Programa de Aceleração do Crescimento (PAC), que visava a reverter 414,5 bilhões de reais nos quatro primeiros anos de projeto. Essa quantia objetivava construir, modernizar e recuperar rodovias, saneamento, malha elétrica, ferrovias, hidrovias, portos e aeroportos por todo o território nacional, além de aumentar a potência energética do país e melhorar o serviço de telecomunicações. Apesar do intuito de reduzir o abismo internacional, o programa criava um abismo inter-regional. Uma grande parte dos investimentos foi destinada às regiões sul e sudeste, já naturalmente privilegiadas.

O PAC visava a ser um plano de desenvolvimento transformador, comparável ao Plano de Metas, do governo de Juscelino, e ao Segundo Plano Nacional de Desenvolvimento, de Ernesto Geisel.

Os investimentos do Plano de Metas, levados a acabo entre os anos de 1957 e 1961, visavam a modernizar o Brasil, investindo US\$2,3 bilhões (Baer, 1996) em 5 áreas: energia, transportes, indústria de base, educação e alimentação.

O II PND, lançado no governo Geisel, visava a aumentar a capacidade energética e a produção de bens de capital. O governo era peça fundamental para o crescimento econômico e a provisão de recursos. Entre 1971-80, o investimento em eletricidade como parcela do PIB era de $2,13 \%$ e em transportes era de 2,03\% (Frischtak, 2012). O investimento da década de 70 contrasta fortemente com o atual, entre os anos de 2001 e 2010, o investimento global médio foi de $2,19 \%$, pouco abaixo do destinado apenas para o setor energético no período militar.

\subsection{Avaliação dos Investimentos Realizados pelo Programa de Aceleração do Crescimento (PAC)}

Entre os anos de 2007 e 2014, os investimentos em infraestrutura apresentaram aumento nominal de $167 \%$, sendo que a maior parte do investimento agregado se destinou ao 
setor de transportes, $\mathrm{R} \$ 53,1$ bilhões, com destaque ao modal rodoviário, $\mathrm{R} \$ 26,1$ bilhões. Houve considerável aumento no investimento em telecomunicações, $134 \%$, bem como no setor de saneamento, 190\%. A queda nominal entre 2014 e 2015 foi de $16 \%$ e, com exceção do setor energético, todos os setores de infraestrutura sofreram cortes reais (Frischtak, 2016).

\begin{tabular}{|c|c|c|c|c|c|c|c|c|c|}
\hline SETOR & $\mathbf{2 0 0 7}$ & $\mathbf{2 0 0 8}$ & $\mathbf{2 0 0 9}$ & $\mathbf{2 0 1 0}$ & $\mathbf{2 0 1 1}$ & $\mathbf{2 0 1 2}$ & $\mathbf{2 0 1 3}$ & $\mathbf{2 0 1 4}$ & $\mathbf{2 0 1 5 E}$ \\
\hline Energia Elétrica & 15,4 & 19,2 & 21,1 & 26,8 & 31,3 & 33,7 & 37,3 & 37,5 & 43,7 \\
\hline Telecomunicações & 12,5 & 24,9 & 18,5 & 16,1 & 21,4 & 23,9 & 22,3 & 29,3 & 19,3 \\
\hline Saneamento & 3,8 & 6,9 & 8,1 & 8,3 & 7,7 & 9,3 & 10,8 & 11,0 & 7,5 \\
\hline Transportes & 17,2 & 23,3 & 30,6 & 37,1 & 36,6 & 40,7 & 51,2 & 53,1 & 38,1 \\
\hline Rodoviário & 9,6 & 12,4 & 18,2 & 22,0 & 21,0 & 18,8 & 24,8 & 26,1 & 19,6 \\
\hline Ferroviário & 3,1 & 5,1 & 3,6 & 5,6 & 6,3 & 6,2 & 7,6 & 9,0 & 5,3 \\
\hline Mobilidade Urbana & 1,5 & 3,2 & 5,6 & 3,7 & 3,5 & 5,0 & 8,2 & 8,9 & 6,2 \\
\hline Aeroportuário & 0,7 & 0,5 & 0,5 & 0,7 & 1,2 & 2,8 & 5,9 & 4,7 & 4,4 \\
\hline Portuário & 1,9 & 1,4 & 1,5 & 4,0 & 3,8 & 7,4 & 4,1 & 3,8 & 2,4 \\
\hline Hidroviário & 0,4 & 0,7 & 1,1 & 1,0 & 0,8 & 0,5 & 0,6 & 0,6 & 0,2 \\
\hline Inv. Infra. Total & 48,9 & 74,3 & 78,2 & 88,3 & 97,0 & 107,6 & 121,6 & 130,9 & 108,6 \\
\hline PIB Nominal & 2.718 & 3.108 & 3.328 & 3.887 & 4.375 & 4.805 & 5.316 & 5.687 & 5.904 \\
\hline Invest./PIB (\%) & 1,8 & 2,39 & 2,35 & 2,27 & 2,22 & 2,24 & 2,29 & 2,30 & 1,84 \\
\hline
\end{tabular}

Tabela 3: Investimento em infraestrutura por setor (em bilhões).

Fonte: Empresas abertas (públicas e privadas); SIAFI; CNI; IPEA data; Portal Transparência; Frischtak (2016).

Para o entendimento mais aprofundado do PAC, é necessário separá-lo em suas duas fases: o PAC 1 e o PAC 2. O "PAC 1", executado entre 2007 e 2010, buscava desenvolver a infraestrutura de 3 esferas: logística (rodovias, ferrovias, aeroportos, hidrovias e marinha mercante); energia (geração, transmissão, petróleo e gás natural); social e urbana. O PAC 1, em 2007, previa $\mathrm{R} \$ 414,5$ bilhões a serem investidos em 4 anos dos quais $\mathrm{R} \$ 169,2$ bilhões em infraestrutura. No entanto, apenas $\mathrm{R} \$ 100$ bilhões foram gastos, custeando um total de 16.542 projetos.

O PAC 2 previa ainda mais investimento pois, além de anunciar novas obras, se comprometia a terminar obras inacabadas do PAC 1. Os investimentos esperados em infraestrutura eram de R \$251,3 bilhões, superando o primeiro PAC EM 48\% (Frischtak, 2016).

O Programa de Aceleração do Crescimento 2 (PAC 2) era dividido em 6 eixos: Cidade Melhor; Comunidade Cidadã; Minha Casa, Minha Vida; Água e Luz para Todos; transportes e energia. O investimento Global previsto era de 621 bilhões dos quais foram efetivamente gastos 434 bilhões. Apenas em infraestrutura, foram gastos 132,9, dos 251,3 bilhões previstos. No início de 2015, foi divulgado o PAC 3, no entanto, este não foi 
implementado até o momento.

O Programa de Aceleração do Crescimento foi significativo pois impulsionou investimentos de ordem social e econômica. No entanto, a análise geral é que o projeto foi falho na execução, com materiais de baixa qualidade, aumento de custos recorrentes e atrasos sistemáticos, aumentando o dispêndio do governo federal. O PAC 1 obteve alguns resultados satisfatórios, o setor de transportes investiu mais que o previsto, acompanhado dos setores hidroviários e rodoviários. O PAC 2 teve desempenho insatisfatório, com o investimento realizado nunca acima do previsto (Frischtak, 2016).

O PAC 2 realizou apenas uma parcela do investimento proposto em vários setores, em especial no setor o de transportes. Os modais mais prejudicados foram: transporte ferroviários (apenas 5,3\% do investimento previsto foi realizado); portuário (apenas $16 \%$ do investimento previsto foi efetivamente realizado) e hidroviário (13,3\% do investimento previsto foi realizado). A exceção foi o investimento no modal rodoviário que obteve desempenho bem melhor que os demais, com $71,8 \%$ do investimento previsto realizado.

Para entender a dimensão do problema da falta de investimento em setores ferroviários e hidroviários, é importante entender o aumento de custo que isso gera para as mercadorias. No Brasil, 61,1\% de tudo que é transportado é feito por meio de rodovias. Enquanto isso, países como Rússia (8\% é feito por meio de rodovias) e Estados Unidos (32\% é feito por meio de rodovias) obtêm vantagens comparativas em relação ao produto brasileiro (ANTT, 2005). Isso ocorre pela vantagem do modal ferroviário em relação ao rodoviário quando a distância é maior que 500 quilômetros.

Além da perda de competitividade, o investimento intensivo no modal rodoviário gera outro problema, o energético. Num estudo feito por Bartholomeu e Caixeta Filho (2008), em 2004 o modal foi responsável por $27 \%$ do consumo final de energia no Brasil e $92 \%$ do consumo de energia nos transportes. É necessário pontuar que os $92 \%$ de participação do modal rodoviário podem refletir a dominância do modal sobre todos os outros como o aeroviário, hidroviário e ferroviário.

O gasto energético aumenta exponencialmente quando a mercadoria é transportada em más condições da estrada. O Brasil possui 1,7 milhões de quilômetros de rodovias dentre os quais, apenas 200 mil quilômetros são asfaltados, deixando o Brasil, segundo Calderón e Sérven (2004), em último lugar na América Latina. A situação é agravada quando se considera que, dos 200 mil quilômetros asfaltados, apenas $28 \%$ possuem situação ótima ou boa.

É razoável supor que o Programa de Aceleração do Crescimento fez crescer o Produto Interno Brasileiro, no curto prazo aumentando a demanda agregada e, no longo, 
aumentando a qualidade e quantidade dos produtos ofertados no país. Apesar disso, a má alocação dos recursos e a ineficiência nos projetos contribuíram para que, em 2016, o produto potencial Brasileiro ficando abaixo de $1 \%$ (Frischtak, 2016).

Estimativas do Banco Mundial apontam que um crescimento sustentado de 4\% demandaria investimentos em infraestrutura entre 4-6\%. Essa quantidade de investimento demanda um projeto de estado eficiente e transparente, com investimentos feitos pelo setor público, porém, direcionados para o setor privado.

\subsection{Avaliação dos Impactos do PAC 1 e PAC 2 por Setor}

\subsubsection{Saneamento}

Houve, segundo relatório do Tribunal de Contas da União, entre os anos de 200714, uma ampliação dos investimentos em saneamento no país. O setor privado aumentou sua participação no setor, notadamente após o marco regulatório. Dos 27,1 bilhões investidos pelo país entre 2007-10, apenas 5,5\% (1,5 bilhões) foram executados pelo PAC 1. O investimento total entre 2011-14 foi de 38,6 bilhões, dos quais 10,1 bilhões executados pelo PAC 2.

O Brasil possui, atualmente, boa cobertura em relação à disponibilidade de água potável ( $83 \%$ da população tem acesso ao abastecimento da rede), apesar de as perdas serem muito altas (SNIS, 2014; Frischtak, 2016). Em relação ao tratamento de esgoto, 40,8\% do esgoto é tratado, abaixo de México (85\%), Uruguai (96\%), Argentina (97\%) e Chile (99\%).

Durante o período de implementação do PAC, houve melhoras nos indicadores de saneamento que, no entanto, foram lentas em relação ao déficit do setor. Em vários projetos houve atrasos e falhas, o que encareceu consideravelmente o valor das obras. Segundo Frischtak (2016), uma amostra sugere que, entre 2010 e 2014, houve aumento médio de $92 \%$ dos prazos, sendo que em $21 \%$ dos projetos houve aumento de custos.

De acordo com o Portal Saneamento Básico (PLANSAB), do Ministério do Meio Ambiente, há necessidade de investimento de 16 bilhões de reais anuais, durante 20 anos, para que o serviço seja universal. A soma de investimentos do PAC 1 e PAC 2 é de R 5,4 bilhões, durante 7 anos, em contraposição aos 65,1 bilhões investidos no total.

Em síntese, houve melhoras, porém, a falta de dados, atrasos e aumento de custos, além de minar a eficácia dos projetos, dificulta a mensuração de seus efeitos na malha sanitária brasileira. 


\subsubsection{Transportes}

Os investimentos do PAC em transportes foram bastante significantes para o montante total no período, representando $41,1 \%$ dos investimentos totais, sendo, $91,8 \%$ destinados à logística e 8,2\% à mobilidade urbana.

Como já foi discutido, o investimento no modal rodoviário foi muito superior aos outros setores, aprofundando ainda mais o papel do modal no transporte de carga e de pessoas.

Segundo a Confederação Nacional de Transportes, o total de rodovias federais pavimentadas passou de 60,5 mil para 66,7 mil quilômetros. No entanto, a densidade da malha pavimentada é de apenas $25 \mathrm{~km} / 1000 \mathrm{~km}^{2}$, muito abaixo de Estados Unidos e China, com 438,1 $\mathrm{km} / 1000 \mathrm{~km}^{2}$ e $459,9 \mathrm{~km} / 1000 \mathrm{~km}^{2}$.

Além disso, a qualidade das rodovias nacionais deixa muito a desejar. De acordo com relatório do Fórum Econômico Mundial, o Brasil se encontra na $121^{\circ}$ primeira posição no ranking de melhores malhas rodoviárias. No caso da malha ferroviária, o país se encontra pouco melhor classificado, atualmente na $89^{\circ}$ posição (Frischtak, 2016).

Apesar de a posição brasileira ser pouco melhor em relação ao modal ferroviário, a extensão da malha brasileira é muito menor que a de países concorrentes. Em comparação aos Estados Unidos, temos pouco mais de $10 \%$ de sua extensão ferroviária (230.000 quilômetros contra 30.000) e até mesmo países como Índia e China possuem o dobro da malha brasileira.

O déficit da malha ferroviária e rodoviária brasileira em relação a países com o mesmo Produto Interno per capita (PIB per capita), se reflete num aumento de custos logísticos para as mercadorias nacionais, reduzindo a competitividade do país. Em média, 11,6\% do custo da mercadoria é logístico, tornando o Brasil um dos países com custo logístico mais alto do mundo (Frischtak, 2016). 


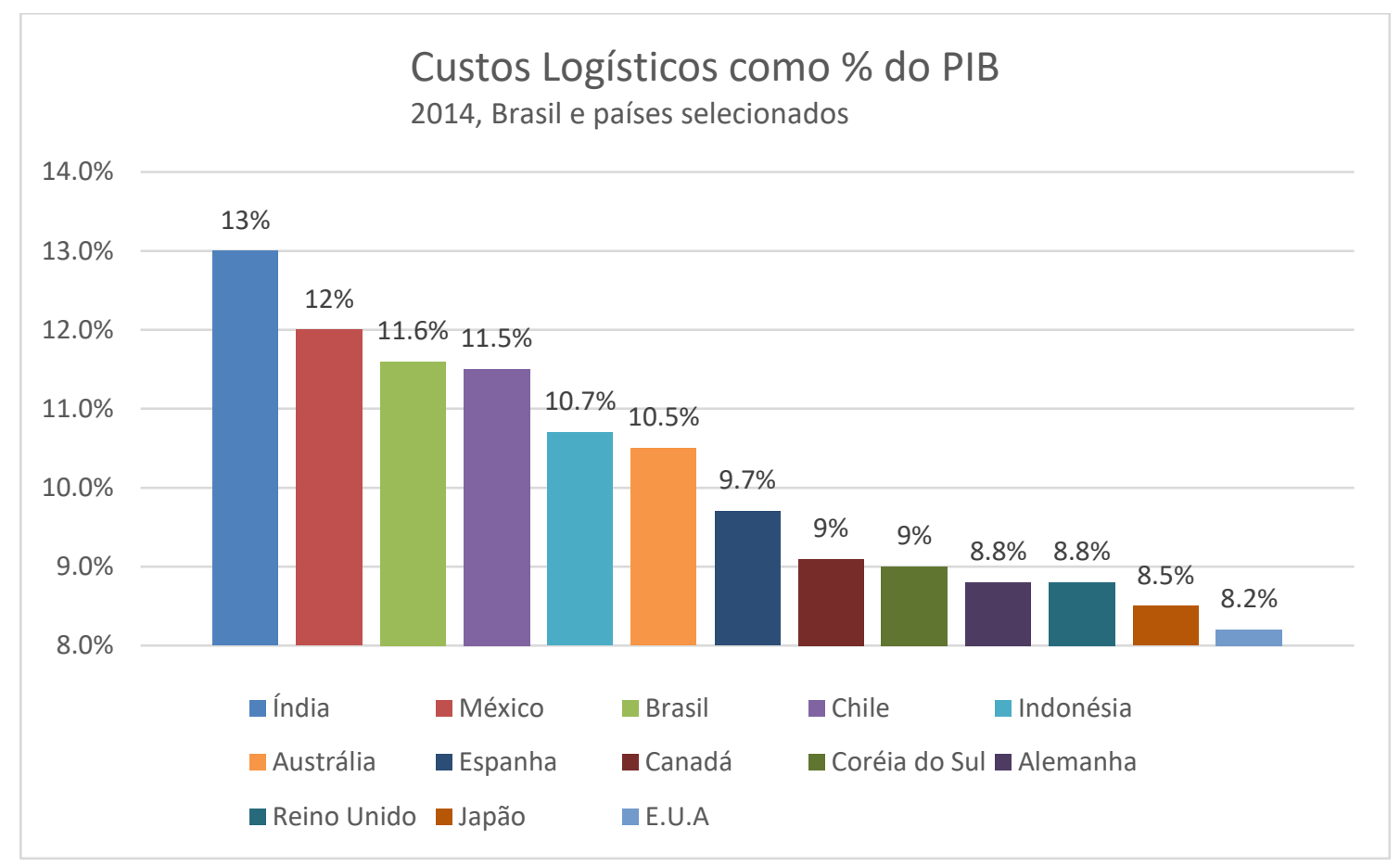

Gráfico 3: Custos logísticos como \% do PIB. Fonte: Armstrong \& Associates; Global Third-Party Logistics (3PL).

Em suma, apesar de os investimentos do PAC serem significativos na fatia global investida entre os anos de 2007-14, o montante total foi aquém do necessário. A eficiência dos projetos foi, também, carente, entre o PAC 1 e o PAC 2. Observou-se um aumento médio dos prazos no setor de transportes de $89 \%$ e o custo médio aumentou $49 \%$ (Frischtak, 2016). O Brasil continua com péssimas malhas rodoviária e ferroviária, a despeito dos investimentos, e o custo logístico continua um dos maiores do mundo.

\subsubsection{Mobilidade Urbana}

O Brasil está numa crise de mobilidade. Um levantamento feito pela empresa “TomTom", responsável por análise de dados de trânsito indica que o Rio de Janeiro está entre as 10 cidades mais engarrafadas do mundo, São Paulo também ocupa lugar de destaque, constando, em 2016, em $71^{\circ}$. Em maio de 2014, segundo dados da Companhia de Engenharia de Trafego, a cidade de São Paulo atingiu um pico de 344 quilômetros de engarrafamento.

Os recentes engarrafamentos e problemas de mobilidade indicam que é preciso avançar muito para que os serviços se tornem universais e adequados. No entanto, mesmo com um aumento significativo de ações propostas do PAC 1 para o PAC 2, a execução de projetos se manteve extremamente baixa (Frischtak, 2016).

Entre 2007 e 2014, o total investido pelo PAC em mobilidade urbana foi R\$9,6 
bilhões, 24,7\% do total no período (Frischtak, 2016). Apesar disso, os indicadores mostram que a mobilidade urbana vem se deteriorando ao longo dos anos.

Os investimentos em mobilidade sofrem dos mesmos problemas do setor de transportes e saneamento. As obras foram mal planejadas, sofrendo aumento de prazos e custos. Segundo Frischtak (2016), estima-se um aumento médio de $30 \%$ nos custos.

O PAC não conseguiu prover a população de um aumento na qualidade do transporte público urbano. Durante o período, a situação piorou. Em 2012, o custo gerado pelo tempo perdido no trânsito atingiu $\mathrm{R} \$ 62,1$ bilhões, não incluindo gastos de combustível e, externalidades criadas (Pinheiro, Frischtak, 2015).

\subsubsection{Energia Elétrica}

Os investimentos realizados pelo PAC foram significativos no setor elétrico. Entre os anos de 2007 e 2014, 42,9\% dos investimentos realizados no setor foram feitos pelo PAC. O pilar e principal legado desses investimentos foi a construção de Belo Monte e a ampliação das linhas de distribuição.

O PAC falhou sistematicamente em reduzir custos e aumentar a qualidade do serviço, priorizando apenas o aumento da oferta e cobertura. De acordo com relatório do Banco Mundial, o Brasil detém perdas elevadas na distribuição de energia (17,08\%). A malha elétrica brasileira falha pelo investimento insuficiente em sua robustez e qualidade. A combinação de elevados custos e baixa eficiência vêm minando o potencial de crescimento brasileiro.

O PAC teve papel importante na expansão da oferta de energia ao investir na extensão da malha e na construção de Belo Monte, não obstante os atrasos e custos elevados. O governo falhou em prover melhor qualidade na oferta e redução de custos de transmissão, isso, aliado a MP 579 de 2012 (posteriormente lei $n^{\circ}$ 12.783) e falta de chuva, culminou na crise energética de 2014. 


\section{Conclusão}

A literatura avalia o investimento como um dos principais responsáveis pela geração de crescimento no longo prazo, redução de desigualdades e pobreza (Calderón e Servén, 2004; Ferreira, 1996; Ferreira e Maliagros, 1998; Bertussi e Ellery, 2012). Investimentos em saneamento, transportes, telecomunicações, mobilidade urbana e energia são fundamentais para ganhos de produtividade, diminuição no custo marginal de instalação e aumento de competitividade. No entanto, a infraestrutura, atualmente, enfrenta dificuldades, com baixo investimento e mal planejamento (Frischtak, 2016; Frischtak, 2008; Leite, 2007; IPEA, 2012).

O presente trabalho visou a investigar o estado atual da infraestrutura no Brasil, focando, para isso, nos setores de energia e saneamento, além da avaliação do Programa de Aceleração do Crescimento (PAC). Analisou-se também a história recentes dos setores de energia e saneamento, bem como a apresentação do panorama geral dos setores. Em relação ao PAC, o estudo averiguou a característica dos investimentos, primeiro de maneira geral, depois isolando os diferentes setores contemplados pelo programa durante suas duas fases (PAC $1 \mathrm{e}$ PAC 2).

Os resultados demonstram que os vários setores de infraestrutura enfrentam dificuldades bastante distintas entre si. O setor de saneamento básico apresenta grandes variações em relação ao percentual de pessoas atendidas entre as diferentes regiões brasileiras (Leoneti et al, 2011; SNIS, 2014). Sendo a coleta e tratamento de esgoto, os pontos de pior resultado. Outro problema são as perdas do sistema de abastecimento de água (Saiani e Toneto, 2010; SNIS, 2014, Frischtak, 2016).

O investimento no setor de saneamento possui vários efeitos benéficos para a população e a economia (Mcgranahan, 2015; Silva e Trinches, 2014; Scriptore et al, 2015). No entanto, a quantidade de recursos necessários para que haja a universalização do atendimento é muito alta, precisando de planejamento e execução (Frischtak, 2016). Para que isso ocorra, é necessário um consenso entre as empresas estaduais e municipais de saneamento. O estudo conclui que as dificuldades enfrentadas pelo setor se relacionam com a ausência de um ente regulador eficiente e de investimentos insuficientes (Frischtak, 2016; Nunes, 2015). Em relação ao PAC, houve atrasos nos prazos e aumentos nos custos, além de baixos investimentos, se comparado a outros setores (Frischtak, 2016).

Em relação ao setor energético brasileiro, os principais desafios são a redução de custos e aumento na qualidade do serviço (IPEA, 2012). O investimento no setor elétrico tem 
se destinado principalmente ao aumento da oferta, com a construção da usina de Belo Monte, e aumento das linhas de transmissão. O Brasil possui centros geradores distantes das grandes cidades, o que aumenta o custo de transmissão. Além disso, a malha elétrica brasileira possui baixa qualidade, o que gera perdas elevadas na transmissão de energia (Frischtak, 2016; Sauer, 2015).

A questão tarifária é outro desafio do setor elétrico brasileiro. A MP 579 (posteriormente transformada em lei) reduziu a lucratividade das geradoras, prejudicando os investimentos no setor. Durante o governo Dilma, as tarifas do setor elétrico foram usadas para segurar a inflação, gerando prejuízos às geradoras. Conciliar modicidade tarifárias com investimentos na qualidade e aumento da produção brasileira são os principais desafios do setor (Sauer, 2015).

Para suprir a necessidade de investimentos em infraestrutura, em 2007 foi criado o PAC. Este falhou em promover os investimentos previstos inicialmente, sofrendo com aumento de prazos e de custos. No entanto, os investimentos realizados pelo programa ajudaram a melhorar o sistema de infraestrutura brasileiro, com o investimento de mais de 200 bilhões nos 7 anos que esteve em vigor (Frischtak, 2016).

Desta forma, o estudo conclui que (i) o papel do estado no investimento, regulação e promoção da infraestrutura brasileira é fundamental. (ii) Um dos grandes problemas dos setores de infraestrutura no brasil é o não cumprimento do que foi planejado. Tanto no setor elétrico, quanto no setor de saneamento básico há uma grande diferença entre o que se propôs a se fazer e o que foi efetivamente feito. (iii) $\mathrm{O}$ regime tarifário imposto deixa muito a desejar e é uma das causas do baixo investimento em infraestrutura no Brasil. No setor elétrico, a modicidade tarifária impôs às geradoras grandes perdas financeiras e, no setor de saneamento, a diferença entre as tarifas cobradas pelas empresas estaduais é enorme, falta, nesse caso, um ente regulador forte. 


\section{Referências Bibliográficas}

ARAUJO, F. C. ; BERTUSSI, G. L. . Empresas Estaduais de Saneamento Básico: Estrutura Tarifária e Situação Econômico-Financeira. In: $2^{\circ}$ Congresso de Contabilidade e Governança UnB, 2016, Brasília - DF. Anais do 2 CCGUnB, 2016.

ARRAES, R.A. E V.K. TELES. Política Fiscal e Crescimento Econômico: Aspectos Teóricos e Evidências Empíricas para as Regiões Brasileiras. Revista Econômica do Nordeste, Fortaleza, v. 32, n. Especial, p. 676-690, 2001.

ASCHAUER, D. Is public expenditure productive? Journal of Monetary Economics, v. 23, p. 177- 200, 1989.

BAER, W. A economia brasileira. São Paulo, 1996.

BANCO CENTRAL. Cotações de fechamento de uma moeda em um período (Janeiro de 2010 e Setembro de 2015). Disponível em: 〈http://www4.bcb.gov.br/pec/taxas/port/ptaxnpesq.asp>. Acesso em: 12 jan 2018.

BARRO, R. Government Spending in a Simple Model of Endogenous Growth. Journal of Political Economy, v. 98, p. 103-125, 1990.

BARRO, R.J. Economic Growth in a Cross Section of Countries. Quarterly Journal of Economics, v. 106, p. 407-443, 1991.

BARTHOLOMEU, D. B; CAIXETA FILHO, J.V. Impactos econômicos e ambientais decorrentes do estado de conservação das rodovias brasileiras: um estudo de caso. Revista de Economia e Sociologia Rural, v.46, n. 3, p. 703-738, 2008.

BERTUSSI, Geovana Lorena; ELLERY JUNIOR, Roberto. Infraestrutura de transporte e crescimento econômico no Brasil. J. Transp. Lit., Manaus, v. 6,n. 4,p. 101-132, 2012. Disponível em: <http://www.scielo.br/scielo.php?script=sci_arttext\&pid=S223810312012000400006\&lng=en\&nrm=iso>. Acesso em: 11 jan 2018.

BORJA, P. C. Panorama do saneamento básico no Brasil: análise situacional dos programas e ações federais. Brasília, DF: Ministério das Cidades, Secretaria Nacional de Saneamento Ambiental, 2011. Disponível em: http://www.saneamentoweb.com.br/sites/default/files/PANORAMA_Vol_3.pdf. Acesso em: 12 jan 2018.

BRITO, A.L.N.P. A regulação dos serviços de saneamento no Brasil: perspectiva histórica, contexto atual e novas exigências de uma regulação pública. Anais do IX Encontro Nacional da ANPUR. p.1080-1093, 2001.

Calderón, C. e L. Servén (2004) The effects of infrastructure development on growth and income distribution. Policy Research Working Paper Series 3400, The World Bank.

CALDERÓN, C. A.; SERVÉN, L. Trends in Infrastructure in Latin America, 1980-2001. World Bank Policy Research Working Paper, n. 3401, set. 2004. 
CÂNDIDO JÚNIOR, J. Os gastos públicos no Brasil são produtivos? IPEA, Texto para Discussão no. 781, 2001.

CANNING, David; PEDRONI, Peter. The effect of infrastructure on long run economic growth. Harvard University, p. 1-30, 2004.

CNI. Diversificação e diferenciais sustentáveis da matriz elétrica brasileira. 2012.

Confederação Nacional do Transporte, "Pesquisa CNT de Rodovias 2015: Relatório Gerencial”, Brasília, 2015.

CUNHA, A. S. Saneamento Básico no Brasil: Desenho Institucional e Desafios Federativos. Texto para Discussão, IPEA, n.1565, 2011.

DE ARAÚJO JÚNIOR, Ignácio Tavares. Investimentos em Infra-estrutura e Crescimento Econômico no Brasil. Revista Economia e Desenvolvimento, v. 5, n. 2, 2006.

DEVARAJAN S.; V. SWAROOP E H.F. ZOU. THE COMPOSITION OF PUBLIC EXPENDITURE AND ECONOMIC GROWTH. JOURNAL OF MONETARY ECONOMICS, VOL. 37, PP. 313-344, 1996.

ESCOLA BRASILEIRA DE ADMINISTRAÇÃO PÚBLICA DA FUNDAÇÃO GETÚLIO VARGAS (EBAP/FGV). Novo modelo de financiamento para o setor de saneamento. Série Modernização do Setor de Saneamento, 1995. Disponível em: <http://www.pmss.gov.br/index.php/biblioteca-virtual/seriemodernizacao-do-setorsaneamento>. Acesso em 12 jan 2018.

FARIA, S.A; FARIA, R.C. Cenários e perspectivas para o setor de saneamento e suas interfaces com os recursos hídricos. Engenharia Sanitária e Ambiental. v.9, n.3, p. 202-210, Jul./Set. 2004.

FERREIRA, P. C.; MALLIAGROS, T. G. Impactos Produtivos da InfraEstrutura no Brasil 1950/95. Pesquisa e Planejamento Econômico, v. 28 (2), p. 315- 338, 1998.

Ferreira, P.C. Investimento em Infraestrutura no Brasil: fatos estilizados e relações de longo prazo. Pesquisa e Planejamento Econômico. v. 26 (2), p. 231-252, 1996.

FGV- A Construção do Desenvolvimento Sustentado: A importância da construção na vida econômica e social do país. Parceria com a União Nacional da Construção - FGV Projetos. São Paulo, agosto, p. 44, 2006.

Freitas, U.R.P; A.A. Castro Neto e I.C. Lôu. Relação entre Gastos Públicos e Crescimento Econômico: uma Análise com Dados em Painel para o Nordeste. Conjuntura e Planejamento, n. 162 , p. 50-57, 2009.

FRISCHTAK, C. Infraestrutura e desenvolvimento no Brasil. In: FERREIRA, P.C.; GIAMBIAGI, F.; PESSÔA, S.; VELOSO, F. (Org.). Desenvolvimento Econômico: uma perspectiva brasileira. Rio de Janeiro: Elsevier, 2013.

Frischtak, C. R. (2012), “A Social-Democracia Brasileira: seu momento de definição”, XXIV 
Fórum Nacional Rumo ao Brasil Desenvolvido (Em Duas Décadas): Estratégia de Desenvolvimento para Transformar Crise em Oportunidade, através de Três Propostas Básicas (Economia do Conhecimento, Mobilização pela Competitividade Nacional e Uso Universal do Mercado de Capitais), aproveitando Grandes Oportunidades. Brasil — "País de Casse Média", Instituto Nacional de Estudos Avançados, Rio de Janeiro, 14 a 17 de maio de 2012.

FRISCHTAK, C.R. O Investimento em Infraestrutura no Brasil: Histórico Recente e Perspectivas. Pesquisa e Planejamento Econômico, v.38, n.2, p.307-348, 2008.

FRISCHTAK, C.R. PAC - Avaliação do Potencial de Impacto Econômico, 2016. Disponível em: $<$ http://cbic.org.br/wpcontent/uploads/2017/11/PAC_Avaliacao_do_Potencial_de_Impacto_Economico_2016.pdf> . Acesso em: 12 jan 2016.

FUNDAÇÃO GETÚLIO VARGAS (FGV); INSTITUTO TRATA BRASIL. Benefícios Econômicos da Expansão do Saneamento Brasileiro. 31 p, Jul. 2010.

G1. Rio de Janeiro é uma das 10 cidades mais congestionadas do mundo, diz pesquisa. 21 de fevereiro de 2017. Disponível em: <https://g1.globo.com/carros/noticia/mesmo-com-melhorario-e-uma-das-10-cidades-mais-congestionadas-do-mundo.ghtml>. Acesso em 12 jan 2018.

GHOSH, Sugata; GREGORIOU, Andros. On the composition of government spending, optimal fiscal policy, and endogenous growth: Theory and evidence. 2006.

GRAMLICH, Edward M. Infrastructure investment: A review essay. Journal of economic literature, v. 32, n. 3, p. 1176-1196, 1994.

HELLER, L. Estudo 20: Saneamento ambiental e recursos hídricos (saneamento básico). 2009. Disponível em: <http://www.cedeplar.ufmg.br/pesquisas/pis/Estudo\%2020.pdf>. Acesso em 12 jan 2018.

INSTITUTO BRASILEIRO DE GEOGRAFIA E ESTATÍSTICA (IBGE). Pesquisa Nacional de Saneamento Básico de 2008. Disponível em: <https://biblioteca.ibge.gov.br/visualizacao/livros/liv45351.pdf $>$. Acesso em 18 jan 2018.

INSTITUTO TRATA BRASIL; CONSELHO EMPRESARIAL BRASILEIRO. Brasil é o $112^{\circ}$ em Ranking de Saneamento Básico Mundial. Disponível em: 〈http://www.tratabrasil.org.br/brasil-e-o-112-em-ranking-de-saneamento-basico-mundial> Acesso em: 18 jan 2018.

IPEA. Infraestrutura e Planejamento no Brasil: Coordenação estatal da regulação e dos incentivos em prol do investimento - o caso do setor elétrico. Relatório de pesquisa, 2012.

IPEA. Infraestrutura Econômica no Brasil: diagnósticos e perspectivas para 2025. Livro 6, volume 1, 2010.

LEITE, A. D. A energia do Brasil. Rio de Janeiro: Elsevier, 2007.

LEONETI, A. B; PRADO, E. L; OLIVEIRA, S. V. W. B. Saneamento básico no Brasil: considerações sobre investimentos e sustentabilidade para o século XXI. Revista de 
Administração Pública. v. 45(2), p. 331-48, Mar./Abr. 2011.

MCGRANAHAN, G. Realizing the right to sanitation in deprived urban communities: meeting the challenges of collective action, coproduction, affordability, and housing tenure. World Development. v. 68, p. 242-253, 2015.

MELO, A. J. M; GALVÃO JÚNIOR, A. C. Regulação e universalização da prestação dos serviços de abastecimento de água. Paranoá. n.10, p. 49-57, 2013.

AGÊNCIA NACIONAL DE TRANSPORTES TERRESTRES (ANTT). Relatório de Gestão $2005 . \quad$ Disponível em: < http://www.antt.gov.br/backend/galeria/arquivos/relatoriogestao_2005.pdf $>$. Acesso em 18 jan 2018.

MINISTÉRIO DAS CIDADES. Panorama do Saneamento Básico no Brasil. Elementos Conceituais para o Saneamento Básico em 2011. Disponível em: $<$ http://bibspi.planejamento.gov.br/bitstream/handle/iditem/271/PANORAMA_Vol_1.pdf?seq uence $=1$. $>$ Acesso em 18 jan 2018.

MINISTÉRIO DAS CIDADES. Plano Nacional de Saneamento Básico. 2014. Disponível em: <http://www.cidades.gov.br/images/stories/ArquivosSNSA/PlanSaB/plansab_texto_edita do_para_download.pdf $>$. Acesso em 12 jan 2018.

MINISTÉRIO DE MINAS E ENERGIA. Balanço Energético Nacional de 2017. Disponível em: $<$ https://ben.epe.gov.br/downloads/Relatorio_Final_BEN_2017.pdf $>$. Acesso em 16 jan 2018.

MONTES, G. C.; REIS, A. F. Investimento público em infraestrutura no período pósprivatizações. Economia e Sociedade, Campinas, v.20, n. 1 (41), p. 167-194, abr. 2011.

MUNNELL, A. Policy Watch: Infrastructure investment and economic growth. Journal of Economic Perspectives, v. 6, n. 4, p. 189-198. 1992.

MUSSOLINI, C. C.; TELES, V. K. Infraestrutura e produtividade no Brasil. Revista de Economia Política, v. 30, n. 4 (120), p. 545-662, 2010.

NASCIMENTO JÚNIOR, E. R; FREIRE, F. S. Valoração de danos ambientais: estudo aplicado à poluição da água via esgotamento sanitário. Anais do XVIII Congresso Brasileiro de Custos. Rio de Janeiro, 07 a 09 de novembro de 2011.

NUNES, V. R. S. O Setor de Saneamento Básico no Brasil: Desafios e Perspectivas. Monografia. Engenharia de Produção da Escola Politécnica. Universidade Federal do Rio de Janeiro, 71 p, 2015.

PEDROSA, V. A. Práticas tarifárias do setor de saneamento brasileiro. Revista Brasileira de Recursos Hídricos. v. 6, p.59-71, Abr./Jun. 2001.

PÊGO FILHO, B.; J.O. CÂNDIDO JR E F. PEREIRA (1999) Investimento e Financiamento da Infraestrutura no Brasil: 1990/2002, IPEA, TD, 680, Brasília. 
PINHEIRO, A. C.; FRISCHTAK, C. R. Mobilidade Urbana: Desafios e Perspectivas para as Cidades Brasileiras. São Paulo, 2015.

RAMIREZ, Miguel D. Public and private investment in Mexico, 1950-90: An empirical analysis. Southern Economic Journal, p. 1-17, 1994.

RASELLA, D. Impacto do Programa Água para Todos (PAT) sobre morbimortalidade por diarreia em crianças do Estado da Bahia, Brasil. Cadernos de Saúde Pública. v. 29(1), p. 4050, Jan. 2013.

Rigolon, F. (1998) O investimento em infraestrutura e a retomada do crescimento econômico sustentado. Pesquisa e Planejamento Econômico, v.28, n.1, p.129-158.

Rocha, F. e A.Giuberti. Composição do Gasto Público e Crescimento Econômico: um estudo em painel para os estados brasileiros. Anais do XXXIII Encontro Nacional de Economia, Natal, $\mathrm{RN}, 2005$.

SAIANI, C. C. S. Déficit de acesso aos serviços de saneamento básico no Brasil. Prêmio IPEACAIXA. 2006.

SAIANI, C. C. S; TONETO JÚNIOR, R. Evolução do acesso a serviços de saneamento básico no Brasil (1970 a 2004). Economia e Sociedade. v. 19, n. 1(38), p.79-106, Abr. 2010.

SAIANI, C. C. S; TONETO JÚNIOR, R.; DOURADO, J. A. Déficit de acesso a serviços de saneamento ambiental: evidências de uma Curva Ambiental de Kuznets para o caso dos municípios brasileiros? Economia e Sociedade. v.22, n.3(49), p. 791-824, Dez. 2013.

SAUER, Ildo Luís. A gênese e a permanência da crise do setor elétrico no Brasil. Revista USP, n. 104, p. 145-174, 2015.

SCRIPTORE, J. S; AZZONI, C. R; MENEZES FILHO, N. A. Saneamento Básico e indicadores educacionais no Brasil. Working Paper Series. n. 28, 2015.

SILVA, G. J. C.; F.G. JAYME JR E R.S MARTINS. Gasto Público com Infraestrutura de Transporte e Performance dos Estados Brasileiros: 1986-2003. (mimeo), 2007.

SILVA, G.J.C. da e FORTUNATO, W.L.L. Infra-Estrutura e Crescimento: Uma Avaliação do Caso Brasileiro no Período 1985-1998. Fórum BNB de Desenvolvimento XII Encontro Regional de Economia, Fortaleza, julho de 2007.

SILVA, S. S; TRICHES, D; Uma Nota sobre Efeitos de Gastos Públicos sobre o crescimento da Economia Brasileira. Revista Brasileira de Economia. v. 68(4), p.547- 559, Out./Dez. 2014.

SISTEMA NACIONAL DE SANEAMENTO BÁSICO (SNIS). Diagnósticos dos Serviços de Água e Esgotos. Período de 2006 a 2014. Disponível em: <http://www.snis.gov.br/diagnosticoagua-e-esgotos>. Acesso em 12 jan 2018.

SOUSA, A. C. A, COSTA, N. R. Incerteza e dissenso: os limites institucionais da política de saneamento brasileira. Revista de Administração Pública. v. 47(3), p. 587- 599, Mai./Jun. 
2013.

TANKHA, S. Lost in Translation: Interpreting the Failure of Privatisation in the Brazilian Electric Power Industry. Journal of Latin American Studies, v. 41 (1), p. 59 - 90, 2009.

TRANSPARENCY INTERNATIONAL. Corruption Perception INDEX 2016. Disponível $\mathrm{em}:<\quad$ https://www.transparency.org/news/feature/corruption_perceptions_index_2016>. Acesso em 18 jan 2018.

UOL. São Paulo Sofre Engarrafamento Recorde de 344 Quilômetros. Disponível em: $<$ https://economia.uol.com.br/noticias/efe/2014/05/23/sao-paulo-sofre-engarrafamentorecorde-de-344-quilometros.htm>. Acesso em 18 jan 2018.

VIZIOLI, T. ; BERTUSSI, G. L. . Infraestrutura energética e crescimento econômico: uma análise empírica para o Brasil. In: XVII Encontro de Economia da Região Sul (ANPEC Sul), 2014, Maringá - Paraná. Anais do XVII Encontro de Economia da Região Sul (ANPEC Sul), 2014.

WINTERS, M. S; KARIM, A. G. Public Service Provision under Conditions of Insufficient Citizen Demand: Insights from the Urban Sanitation Sector in Indonesia. World Development. v.60, p. 31-42, 2014.

WOLFRAM, C.; SHELEF, O. e GERTLER, P. How Will Energy Demand Develop in the Developing World? Journal of Economic Perspectives, v. 26(1), p. 119-138, 2012.

WORLD HEALTH ORGANIZATION (WHO); UNICEF. Progress on Sanitation and Drinking-Water. $2013 . \quad$ Disponível em: <http://apps.who.int/iris/bitstream/10665/81245/1/9789241505390_eng.pdf>. Acesso em 12 jan 2018. 